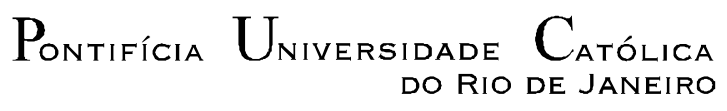

Luiz Eduardo Santos Torres

\title{
Proposta de Modelo de Gestão Universitária Baseado em Sustentabilidade: Aplicação ao Caso PUC-Rio
}

Dissertação apresentada como requisito parcial para obtenção do grau de Mestre pelo Programa de PósGraduação em Engenharia de Produção do Departamento de Engenharia Industrial da PUC-Rio.

Orientador: Prof. Silvio Hamacher 


$$
\text { Pontifícia } \text { Universidade }_{\text {Do Rio de Janeiro }} \text { Cálica }_{\text {dato }}
$$

\section{Luiz Eduardo Santos Torres}

\section{PROPOSTA DE MODELO DE GESTÃO UNIVERSITÁRIA BASEADO EM SUSTENTABILIDADE: APLICAÇÃO AO CASO PUC-RIO}

Dissertação apresentada como requisito parcial para obtenção do grau de Mestre pelo Programa de Pós-Graduação em Engenharia de Produção da PUC-Rio. Aprovada pela Comissão Examinadora abaixo assinada.

Prof. Silvio Hamacher

Orientador

Departamento de Engenharia Industrial - PUC-Rio

Prof. Luiz Carlos Scavarda do Carmo Pontifícia Universidade Católica do Rio de Janeiro - PUC-Rio

Prof. Josafá Carlos de Siqueira Pontifícia Universidade Católica do Rio de Janeiro - PUC-Rio

Prof. José Eugenio Leal Coordenador Setorial do Centro Técnico Científico - PUC-Rio 
Todos os direitos reservados. É proibida a reprodução total ou parcial do trabalho sem autorização da universidade, do autor e do orientador.

\section{Luiz Eduardo Santos Torres}

Graduou-se em Engenharia de Produção pela PUC-Rio em 2007. Especializou-se em Inteligência de Negócios pelo Departamento de Engenharia Elétrica da PUC-Rio e em Finanças Corporativas pelo IAG/PUC-Rio. Atualmente trabalha como Assessor de Planejamento da Vice-Reitoria Administrativa da PUC-Rio.

Ficha Catalográfica

Torres, Luiz Eduardo Santos

Proposta de modelo de gestão universitária baseado em sustentabilidade: aplicação ao caso PUC-Rio / Luiz Eduardo Santos Torres ; orientador: Silvio Hamacher. 2012.

70 f. : il. (color.) ; $30 \mathrm{~cm}$

Dissertação (mestrado)-Pontifícia Universidade Católica do Rio de Janeiro, Departamento de Engenharia Industrial, 2012.

Inclui bibliografia

1. Engenharia Industrial - Teses. 2. Gestão universitária. 3. Sustentabilidade. 4. Gestão financeira. 5. Responsabilidade social. 6. Responsabilidade ambiental. 7. Tecnologia da informação. I. Hamacher, Silvio. II. Pontifícia Universidade Católica do Rio de Janeiro. Departamento de Engenharia Industrial. III. Título.

CDD: 658.5 


\section{Agradecimentos}

Gostaria de agradecer ao Prof. Silvio Hamacher pelo constante apoio e aprendizado desde a Graduação.

Agradeço também ao Prof. Josafá Carlos de Siqueira S.J, ao Prof. Luiz Carlos Scavarda do Carmo e ao Prof. Luiz Felipe Roriz Scavarda do Carmo pela participação na banca examinadora.

À PUC-Rio, agradeço pelos auxílios concedidos, sem os quais este trabalho não poderia ter sido realizado.

Ao Projeto SUMA e seus integrantes, agradeço a oportunidade e disponibilidade em participar da Pesquisa.

Para Dani, um agradecimento especial pela ajuda e pelo constante carinho e dedicação nos desafios que encaramos em conjunto. Amo você.

Ao meu filho Marcelo, agradeço pela enorme força e felicidade geradas com seu nascimento!

Aos meus pais, irmãos e sobrinhos, agradeço por todo o suporte e amor que me ajudaram a chegar até aqui.

Agradeço também aos amigos da Vice-Reitoria Administrativa, Superintendência Administrativa, SGU, APlan e NExO pela convivência e amizade. 


\section{Resumo}

Torres, Luiz Eduardo Santos; Hamacher, Silvio (Orientador). Proposta de Modelo de Gestão Universitária baseado em sustentabilidade: aplicação ao caso PUC-Rio. Rio de Janeiro, 2012. 70p. Dissertação de Mestrado - Departamento de Engenharia Industrial. Pontifícia Universidade Católica do Rio de Janeiro.

Este trabalho propõe um modelo de gestão universitária sob a ótica da sustentabilidade de Instituições de Ensino Superior (IES), baseado em quatro pilares: Excelência em Ensino e Pesquisa, Gestão Financeira, Responsabilidade Social e Responsabilidade Ambiental, apoiados por Tecnologia da Informação. Inicialmente o modelo proposto foi validado e aplicado ao caso da PUC-Rio, com o foco na Gestão Universitária. Posteriormente um questionário foi aplicado em onze IES da América Latina e Europa para avaliar o grau de desenvolvimento destas instituições face aos quatro pilares do modelo de sustentabilidade proposto. A partir deste questionário foi possível identificar as melhores práticas de sustentabilidade em IES e confrontá-las com os resultados da PUC-Rio.

\section{Palavras-Chave}

Gestão universitária; sustentabilidade; gestão financeira; responsabilidade social; responsabilidade ambiental; tecnologia da informação. 


\section{Abstract}

Torres, Luiz Eduardo Santos; Hamacher, Silvio (Advisor). Proposition of an University Management Model based on Sustainability: case study of PUC-Rio. Rio de Janeiro, 2012. 70p. Msc. Dissertation - Departamento de Engenharia Industrial. Pontifícia Universidade Católica do Rio de Janeiro.

This work proposes a model of university management from the perspective of sustainability, based on four pillars: Excellence in Education and Research, Financial Management, Social Responsibility and Environmental Responsibility, supported by information technology. Initially the model was validated and applied to the case study of PUC-Rio, with focus on University Management. Subsequently, a questionnaire was administered in eleven Latin American and European Universities to assess the degree of development of these institutions, based on the four pillars of sustainability proposed by the model. With the results of this survey, it was possible to identify some of the best practices of sustainability in those Universities and confront them with the results of PUC-Rio.

\section{Keywords}

University management; sustainability; financial management; social responsibility; environmental responsibility; information technology. 


\section{Sumário}

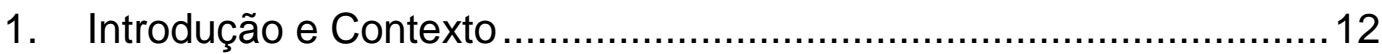

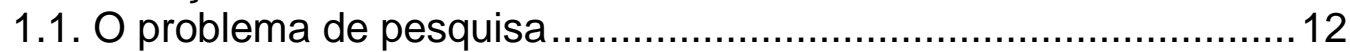

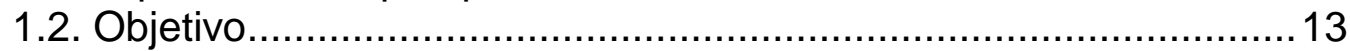

1.3. Relevância do Tema ................................................................. 13

1.4. Estrutura da Dissertação …………….....................................14

2. Referencial Teórico................................................................

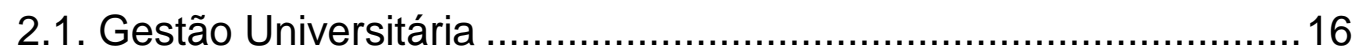

2.1.1. Excelência em Ensino e Pesquisa ...................................... 18

2.1.2. Gestão Financeira ...........................................................19

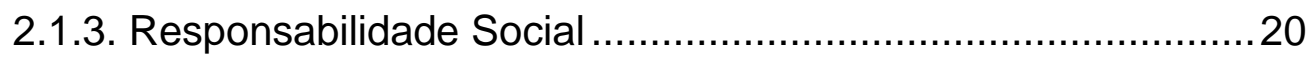

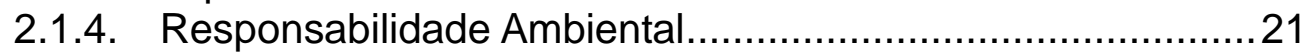

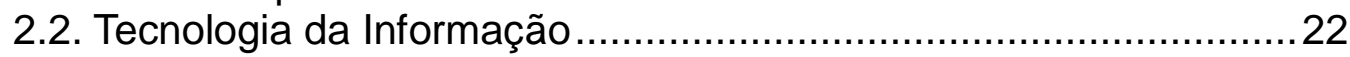

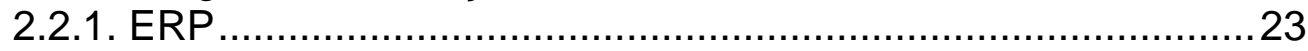

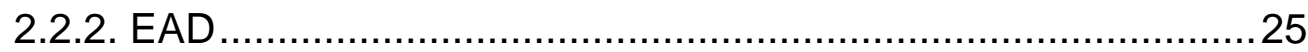

2.3. Modelo de Gestão Universitária Baseado em Sustentabilidade ....26

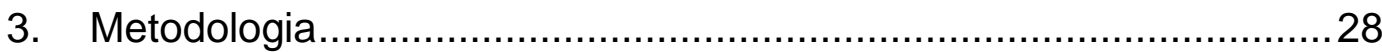

3.1. Tipo, Estratégia e Método de pesquisa.......................................28

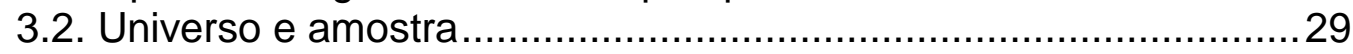

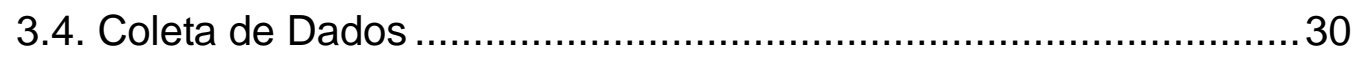

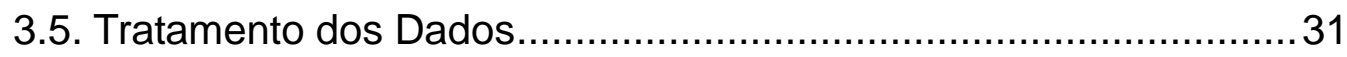

3.6. Fases da Pesquisa .............................................................. 31

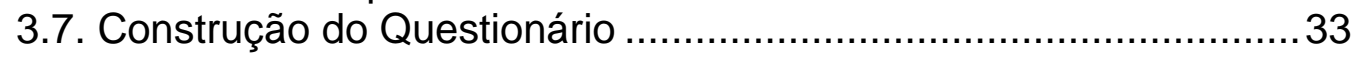

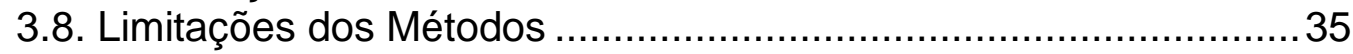

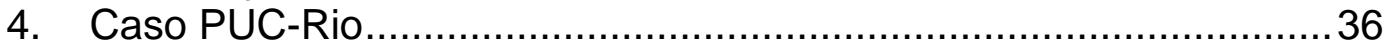

4.1 Excelência em Ensino e Pesquisa ...............................................38

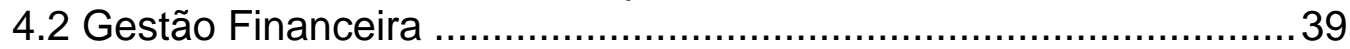

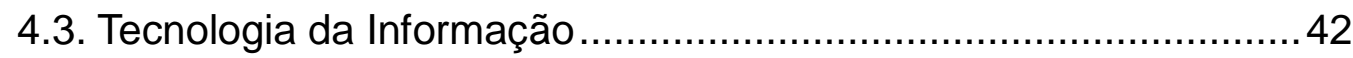

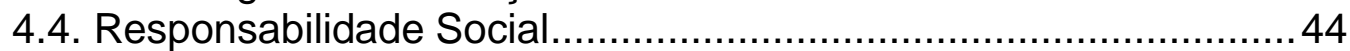

4.5. Responsabilidade Ambiental ...................................................... 45

5. Avaliação das universidades da América Latina e Europa .................44

5.1 Excelência em Ensino e Pesquisa ................................................4 47

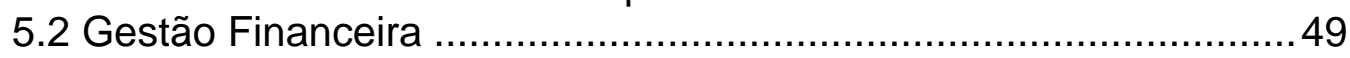

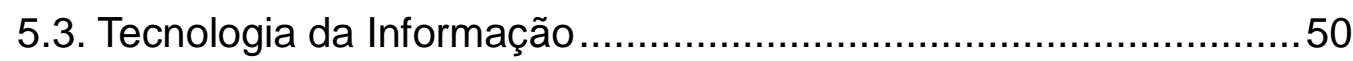

5.4. Responsabilidade Social....................................................... 52

5.5. Responsabilidade Ambiental .....................................................53

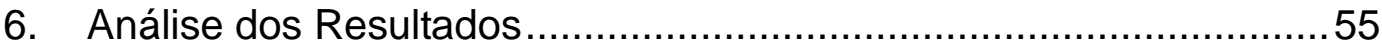

6.1 Excelência em Ensino e Pesquisa ..............................................55

6.2 Gestão Financeira ...............................................................56

6.3. Tecnologia da Informação ...................................................... 57

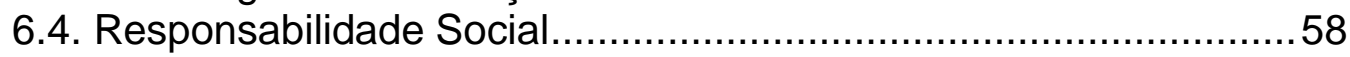

6.5. Responsabilidade Ambiental ..................................................58

6.6. Avaliação das Melhores Práticas ..................................................59

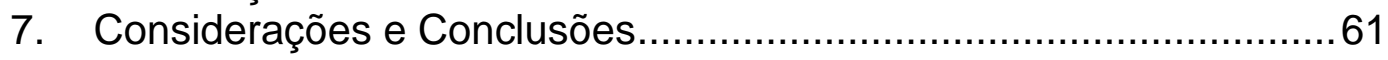

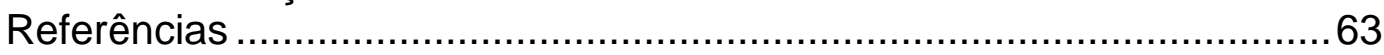

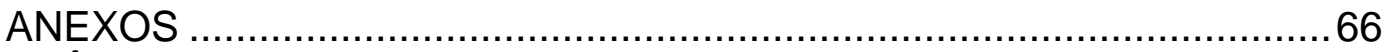

APÊNDICES 


\section{Lista de Figuras}

Figura 1 - Modelo PDCA (Fonte: Tauchen e Brandli, 2006)....................22

Figura 2 - Fornecedores de ERP (Fonte: Gartner Group, 2012) .............24

Figura 3 - Fornecedores de BI (Fonte: Gartner Group, 2012) ................25

Figura 4- Evolução de Matrículas de Graduação em EAD (Fonte: INEP,

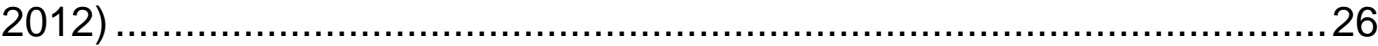

Figura 5 - Modelo Geral da Pesquisa (Fonte: Elaborado pelo autor) ......27

Figura 6- Etapas da Pesquisa (Fonte: Elaborado pelo autor) ...................32

Figura 7- Etapas da Pesquisa (Fonte: Elaborado pelo autor) ...................32

Figura 8 - Organograma da PUC-Rio (Fonte: PUC-Rio, 2012)...............37

Figura 9 - Modelo Aplicado ao Caso PUC-Rio (Fonte: Elaborado pelo autor) 


\section{Lista de Tabelas}

Tabela 1- Síntese Estatística de Excelência em Ensino e Pesquisa ........48 48

Tabela 2- Síntese Estatística de Gestão Financeira...............................49

Tabela 3- Síntese Estatística de Responsabilidade Social .......................53

Tabela 4- Síntese Estatística de Responsabilidade Ambiental .................54 


\section{Lista de Quadros}

Quadro 1 - Lista de Universidades respondentes do Questionário 29 


\section{Lista de Gráficos}

Gráfico 1 - Manutenção sistemas de TI ......................................... 51

Gráfico 2 - Módulos Suportados ......................................................52 


\section{Introdução e Contexto}

O Brasil passa por um novo momento político e econômico, cuja estabilidade em ambos os pontos nunca tinha sido experimentada. Em um novo posto de influência mundial, apresentando um crescimento sustentável, o Brasil passa a ter que focar os investimentos na Educação, não apenas a Educação básica, mas também a Educação Superior. Grandes nações, líderes mundiais, apresentam modelos bem enraizados de políticas educacionais, que ajudam a perpetuar seus poderes econômicos, tecnológicos e políticos.

Podemos afirmar que o Brasil do futuro terá que passar por um novo modelo educacional, que já está em curso com ações ainda incipientes, mas baseadas nesse novo objetivo de criar subsídios necessários para um protagonismo mundial do país.

A nova fase na educação superior terá que se desenvolver através da Gestão Universitária, com enfoque cada vez maior para a sua sustentabilidade.

Lima (2006) afirma que o desenvolvimento sustentável é aquele que se torna factível ao longo do tempo, demonstrando-se acessível às gerações atuais sem comprometer as gerações futuras. Portanto, o desenvolvimento das universidades será baseado nas necessidades atuais e futuras, em todos os sentidos funcionais das instituições, como questões econômico-financeiras, relações com a sociedade, relações com o meio-ambiente e sua qualidade de entrega do conhecimento para o ensino e para a pesquisa.

Nesse sentido, o presente estudo volta-se à questão do ensino universitário através de uma avaliação da Pontifícia Universidade Católica do Rio de Janeiro (PUC-Rio), Instituição Privada de Ensino Superior (IPES) sem fins lucrativos, no que se refere a sua gestão universitária. Para embasar a avaliação, uma comparação com Instituições de Ensino Superior (IES) da América Latina e Europa foi realizada.

\subsection{O problema de pesquisa}

Fundamentado no modelo proposto de sustentabilidade em IES, formulou-se a seguinte pergunta que embasará a dissertação:

Como o modelo de gestão universitária da PUC-Rio pode ser avaliado em 
relação à sustentabilidade, comparando-o com outras IES da América Latina e da Europa?

\subsection{Objetivo}

O objetivo deste estudo é propor um modelo de gestão universitária, baseado em 4 pilares chave: Excelência em Ensino e Pesquisa, Gestão Financeira, Responsabilidade Social e Responsabilidade Ambiental, que utilizam a Tecnologia da Informação para apoiar suas finalidades, aplicando-o na PUC-Rio, sendo respaldada através de uma comparação com outras IES da América Latina e Europa.

\subsection{Relevância do Tema}

A educação superior vem apresentando grande crescimento desde a última década. De acordo com UNESCO (2012), o Brasil é o quinto mercado de ensino superior, entre todas as nações do mundo, sendo ainda o maior dentro da América Latina.

É importante observar que dentro dos 5 maiores mercados, 4 são representantes do grupo de países chamados de BRIC (Brasil, Rússia, Índia e China), sendo inclusive o primeiro lugar (China) pertencente ao grupo.

Em levantamento de dados realizado pelo INEP (2012), o Brasil possuía 2.378 Instituições de Ensino Superior, sendo considerados Universidades, Centro Universitários, Faculdades, Institutos Federais e CEFET. Das 2.378 instituições, $88,3 \%$ (ou 2.100) são privadas. Foi ainda identificado um total de 5,45 milhões de matriculados em Cursos de Graduação Presenciais, dos quais 73,2\% (ou 3,99 milhões) em Instituições de Ensino Superior Privadas. Apesar do esforço dos Governos Federal e Estaduais em aumentar as vagas atendidas pelas Instituições de Ensino Superior Públicas, a grande parte da demanda de vagas em IES dos últimos anos está sendo absorvida pelas IES Privadas.

A maior parte das IPES limita-se ao ensino de graduação e extensão. O número é pequeno no que se refere às IES Privadas que realizam pesquisa, e menor ainda para as que atingem grande número de áreas de estudo em suas pesquisas. Esse é um pequeno nicho marcado por instituições de renome e tradição, dentre as quais se situa a Pontifícia Universidade Católica do Rio de 
Janeiro. Apontada por estudo da Revista BNDES Setorial como sendo, pela segmentação do mercado educacional, pertencente ao Quadrante dos Sonhos, que foi definido por Garcia (2005) como uma posição "difícil de ser obtida, atualmente ocupada apenas por instituições de grande tradição ou sem concorrência acirrada", a PUC-Rio é considerada uma das melhores Instituições de Ensino Superior do País, sendo considerada por algumas avaliações a melhor Privada.

Ao longo dos tempos, a PUC-Rio tem recebido prêmios, conceitos e boas classificações de diversos institutos e avaliações de sua Excelência em Ensino. De acordo com CPA PUC-Rio (2012), são apresentados alguns desses destaques ao longo do ano de 2011:

- A Melhor Universidade privada brasileira, a $2^{\mathrm{a}}$ Universidade melhor colocada no ranking do Estado do Rio de Janeiro e a $16^{\mathrm{a}}$ colocada no ranking geral das universidades brasileiras no Índice Geral de Cursos (IGC) - 2011

- Conceito máximo para 14 de seus cursos de graduação e 14 conceitos "muito bom" no Guia do Estudante - 2011

- A $15^{\mathrm{a}}$ melhor IES da América Latina, sendo a $6^{\mathrm{a}}$ IES brasileira, e a $1^{\text {a }}$ IES brasileira Privada no QS Latin American Ranking - 2011.

Tendo em mente o lugar ocupado pela PUC-Rio na educação nacional e internacional, e as constantes discussões sobre Gestão Universitária, desenvolvimento e autonomia das Universidades (ROMANO, 2008), nota-se que o tema é de muita importância no cenário atual.

\subsection{Estrutura da Dissertação}

Além do capítulo de Introdução, o presente trabalho está divido em outros 6 capítulos, resumidamente apresentados a seguir.

No Capítulo 2 são apresentados uma revisão de conceitos de Gestão Universitária, subdividida pelos 4 pilares do estudo (Excelência em Ensino e Pesquisa, Gestão Financeira, Responsabilidade Ambiental e Responsabilidade Social), e conceitos de Tecnologia da Informação, sendo apresentado o modelo de Gestão Universitária com foco na Sustentabilidade. 
No Capítulo 3, a metodologia de pesquisa é detalhada, que consiste em um Estudo de Caso da PUC-Rio em uma avaliação de seu modelo perante outras universidades da América Latina e Europa.

No Capítulo 4, o modelo PUC-Rio é apresentado, com o detalhamento de suas ferramentas de gestão e de TI.

No Capítulo 5, é analisado os questionários das Universidades da América Latina e Europa.

No Capítulo 6, é realizada a comparação e avaliação do modelo PUC-Rio em relação aos resultados do Capítulo 5.

Por fim, no Capítulo 7, são apresentadas conclusões e propostas para trabalhos futuros. 


\section{Referencial Teórico}

Para se chegar até o problema de pesquisa é preciso delinear a estruturação do modelo, além de inserir o estudo de caso no contexto da Gestão de Universitária. Serão apresentados conceitos de Gestão Universitária, abertos pelos pilares formadores da Sustentabilidade (Excelência em Ensino e Pesquisa, Gestão Financeira, Responsabilidade Ambiental e Responsabilidade Social). A Tecnologia da Informação (TI) como facilitadora dessa estrutura também será conceituada. Por fim, é apresentado o modelo de Gestão Universitária no conceito da sustentabilidade.

\subsection{Gestão Universitária}

As Universidades são organizações com peculiaridades em relação a outros tipos de Instituições. Seja uma Instituição de Ensino Superior (IES) Privada ou Pública, o modelo de funcionamento das instituições demandam características flexíveis, com forte presença do corpo Docente. A exceção seriam as IES Privadas capitalistas, com foco no retorno financeiro para os acionistas. O grande exemplo deste grupo seria a Universidade Estácio de Sá, que em 2007 realizou seu IPO (oferta pública inicial de ações) na Bolsa de Valores de São Paulo, e em 2008 passou a ser controlada pela GP Investimentos.

De acordo com SOUZA (2007), as leis e reformas do ensino superior direcionaram as mudanças de foco, como práticas, modelos e estilos que demonstram a transformação das IES em empresas com abrangência global.

Marback Neto apud Souza (2007) delineia aspectos de alguns modelos de gestão universitária em IES, como o Burocrático (presença marcante do formalismo, impessoalidade e profissionalismo; bloquear a criatividade da área acadêmica pelo excesso de atendimento dos padrões estabelecidos pela área administrativa), o Político (conciliar fatores como consumo e conflito com pressupostos burocráticos; as decisões ficam a cargo de pequenos grupos, que algumas vezes constituem-se grupos de interesse fora da estrutura hierárquica), o Anarquia Organizada (contradiz o papel da universidade de ser uma organização de vanguarda, pois trabalha de forma realista; decisões são tocadas sem um estudo prévio ou uma análise mais apurada, pois tem o objetivo determinado de sanar os 
problemas), o Cibernético (o gestor tem a tarefa de proteger a organização, assumindo seus papéis: ajusta o sistema; garante a sobrevivência da organização) e o Colegiado. Em geral, as IES fazem uso do modelo Colegiado, com as características listadas a seguir:

- estrutura bastante igualitária, com relações predominantemente informais;

- decisões tomadas por consenso;

- dirigente eleito pelos pares, isto legitima;

- confiança é condição sine qua non;

- modelo mais viável em universidades

É possível identificar a forte presença de Professores em cargos administrativos das Instituições, devido à necessidade do foco acadêmico, mesmo em áreas não relacionadas diretamente com o objetivo fim. A flexibilidade das relações na gestão e uma estrutura de igualdade dentro do corpo Docente facilitam a discussão e o consenso nas decisões estratégicas.

Importante salientar que os desdobramentos e consequências determinantes para a Gestão Universitária ocorrem tanto interna quanto externamente, envolvendo, assim, várias partes envolvidas (stakeholders): funcionários; professores; alunos; sociedade e governo.

As Universidades brasileiras estão sujeitas, além do acompanhamento e avaliação interna de suas ações e atividades, à avaliação de sua gestão universitária por órgãos externos competentes, que recebem do Governo Federal essa missão.

Por exemplo, o Instituto Nacional de Estudos e Pesquisas Educacionais (INEP) possui o Sistema Nacional de Avaliação da Educação Superior (SINAES). De acordo com o INEP (2012), o SINAES abrange três pontos principais: a avaliação de instituições; a avaliação dos cursos e o desempenho dos alunos. A Avaliação Institucional, que é de importância deste trabalho, é pautada em 10 dimensões:

1. Missão e Plano de Desenvolvimento Institucional (PDI);

2. Política para o ensino, a pesquisa, a pós-graduação e a extensão;

3. Responsabilidade social da IES;

4. Comunicação com a sociedade; 
5. As políticas de pessoal, as carreiras do corpo docente e técnicoadministrativo;

6. Organização de gestão da IES;

7. Infraestrutura física;

8. Planejamento de avaliação;

9. Políticas de atendimento aos estudantes;

10. Sustentabilidade financeira.

É possível observar que a Gestão Financeira e a Responsabilidade Social são dimensões explícitas do SINAES. Outras tantas dimensões estão associadas a Excelência em Ensino e Pesquisa, como são os casos das dimensões 1,2,5,8 e 9. Entretanto, é clara a falta de dimensões explícitas para a Responsabilidade Ambiental, ponto tão discutido e de interesse pleno pela sociedade.

No cenário atual, vários assuntos têm sido debatidos com relação à eficiência e eficácia da Gestão Universitária, levando-se em conta a competitividade atual. Dentre os temas mais recorrentes na literatura, foram identificados pilares chave que influenciam a tomada de decisão e contribuem para o gerenciamento do dia-a-dia universitário.

Passa-se então à análise mais detalhada de cada um dos pilares.

\subsubsection{Excelência em Ensino e Pesquisa}

O grau a ser atingido de Excelência Acadêmica de uma IES é que determinará, em termos estruturais, a forma como a Gestão Universitária será concebida.

Segundo Sobral (2009), a Excelência Acadêmica orienta diretamente a produção do conhecimento, constituindo uma tendência prioritária da política científica promovida principalmente pelos mecanismos de avaliação do $\mathrm{CNPq}$ e da CAPES.

Um exemplo de importância desta dimensão para a Gestão Universitária, no que tange pelo menos à pós-graduação, é o Programa de Excelência Acadêmica PROEX da CAPES - Coordenação de Aperfeiçoamento de Pessoal de Nível Superior. Este programa tem como objetivo manter um padrão de qualidade em cursos de pós-graduação, cujas IES recebem uma dotação orçamentária para investimento em laboratórios, bolsas de estudo, etc (CAPES, 2012). 
Ações da iniciativa privada também fomentam a Excelência, a FUCAPE Business School (FUCAPE, 2012), juntamente com a ArcelorMittal Tubarão, promovem o Prêmio Excelência Acadêmica, porém com outro foco. Vários trabalhos são submetidos aos avaliadores do Prêmio, que prioriza a disseminação de conhecimentos.

Por meio de pesquisas de programas semelhantes em várias universidades do país, notou-se claramente que a Excelência Acadêmica está voltada para ações ligadas à infraestrutura (laboratórios, incubadoras de empresas, bibliotecas, bases de ensino à distância), publicações de artigos pelos docentes e ações inovadoras de modo geral por meio de participações em projetos de pesquisas. A Excelência Acadêmica está diretamente ligada ao desempenho institucional da IES.

No item 1.3 desta dissertação, Relevância do Tema, foram citados os reconhecimentos dos quais a PUC-Rio recebeu como Instituição de Ensino Superior, mostrando seu ótimo desempenho nacional e internacional. Um ranking citado foi o QS Latin American Ranking (QS RANKINGS, 2012). Os indicadores utilizados por este ranking são ponderados por níveis que consideram apropriados: reputação acadêmica (40\% na contagem dos pontos), reputação da instituição como empregadora (10\%), relação do corpo docente com os estudantes (20\%), citações por docente $(20 \%)$, número de docentes estrangeiros $(5 \%)$ e estudantes estrangeiros $(5 \%)$.

\subsubsection{Gestão Financeira}

Apesar de atividade meio para uma Instituição de Ensino, a Gestão Financeira é um pilar de necessidade objetiva, já que o equilíbrio financeiro é que determinará o funcionamento da Instituição em tempos seguintes. A grande questão que norteia a Gestão Financeira das IES é a diversificação das Fontes de Financiamento. De acordo com Queiroz et al (2011), a Instituição deve identificar formas para que recursos financeiros estejam disponíveis para atender demandas de suas estratégias.

Todavia a Gestão Financeira não se limita à identificação de Fontes de Financiamento. Seu papel central é de cumprimento de suas obrigações perante seus clientes e fornecedores, com atividades de Contas a Pagar, Contas a Receber, Tesouraria, Contabilidade e outros. Nesse sentido, o acompanhamento dos 
processos financeiros permite identificar melhoras na eficiência da Universidade, e o Gestor Financeiro possui esse enfoque no seu dia-a-dia.

Entretanto, a execução Financeira cabe à Administração Central da Instituição, onde são realizados os pagamentos e recebimentos. Os departamentos, setores, gerências ou unidades utilizam de um Modelo Orçamentário Institucional para gerir suas necessidades de funcionamento, pleitear investimentos e planejar seu futuro, de curto, médio e até mesmo longo prazo. Welsch (1973) afirma que a tradução formal das políticas institucionais, planejamento e metas realizadas pelo mais alto nível administrativo da Instituição, é o Orçamento.

Outra função primordial do Gestor Financeiro é com relação às suas obrigações legais de demonstrações financeiras e contábeis, além dos relatórios de análise interna que orientam a alta administração. De acordo com Marion (2007), são esses documentos que propiciam a medição de resultados das instituições, tendo assim avaliações de seu desempenho, fornecendo diretrizes para o auxílio à tomada de decisão.

\subsubsection{Responsabilidade Social}

A Responsabilidade Social atualmente tem sido a porta de entrada tanto de empresas quanto de IES para a inserção na sociedade. Ter a sua imagem associada a boas práticas sociais traz bons frutos no médio e longo prazo. De fato, Tachizawa (2002) afirma que para trilhar um caminho pautado na Responsabilidade Social deve-se compreender o papel dos seus atores sociais e o funcionamento da organização no seu contexto social, ambiental e econômico.

Tachizawa (2002) define Responsabilidade Social como uma maneira de conduzir as empresas e instituições de tal modo que seja definida uma parceira associada à distribuição de responsabilidades no desenvolvimento social. Ganha a sociedade e a Instituição.

O tema Responsabilidade Social faz com que se pense globalmente. A sociedade está cada vez mais entrelaçada e conectada entre si, fazendo com que as ações locais repercutam de uma forma mais impactante e transformadora de valores.

A União Européia, por exemplo, possui políticas prioritárias para amparar e orientar cada vez mais empresas e governos. Nas próprias palavras da Comissão 
Européia (2012), o desenvolvimento sustentável abrange dimensões sociais, ambientais e econômicas, sendo um objetivo predominante da União Européia. A sustentabilidade e a competitividade são dimensões que se reforçam mutuamente. Observando os indicadores utilizados para a mensuração da Responsabilidade Social de empresas, notou-se que envolvem temas recorrentes em IES no Brasil.

A Comissão Européia representa os interesses gerais da União Européia, assumindo um papel importante nas negociações internacionais.

A propósito, a aplicação dos questionários desta pesquisa ocorreu durante o evento do SUMA - IV Taller SUMA Montevideo Uruguay, que é financiado pela Comissão Européia. Mais detalhes serão delineados no capítulo destinado à Metodologia.

\subsubsection{Responsabilidade Ambiental}

A questão ambiental para as IES é de suma importância. Não apenas pelo seu papel como empresa e suas responsabilidades junto à sociedade, mas também pelo caráter de exemplo e de propagação do conhecimento ambiental. Os estudantes, que hoje dedicam em média 5 anos de suas vidas dentro de um IES, serão os administradores de grandes corporações, políticos do poder legislativo e executivo, servidores do estado, juízes e promotores do amanhã. A transferência do conhecimento das necessidades e cuidados relativos ao meio-ambiente, além da prática através da vivência na IES de ações efetivas para minimizar o impacto ambiental, são direcionadores para a formação dos jovens que terão papel central nas decisões futuras.

Um exemplo de engajamento ambiental recente é a Rio+20 - Conferência das Nações Unidas sobre Desenvolvimento Sustentável. A PUC-Rio foi um dos centros de discussões acerca das principais questões ambientais e científicas atuais, desempenhando um papel fundamental no desenvolvimento da massa crítica nos seus alunos. O impacto de um evento dessa magnitude nos alunos de uma universidade, inserida diretamente no contexto na cidade sede do encontro, forma um marco na gestão universitária e será, definitivamente, lembrado pelos cursos mais envolvidos no assunto. Os alunos da PUC-Rio tiveram o privilégio de participar ativamente de discussões de nível mundial.

Assim, a própria gestão universitária da Universidade caso desta 
Dissertação sofreu um enorme impacto, assim como outras universidades do mundo inteiro, com alunos em plena geração e disseminação de conhecimento.

Tauchen e Brandli (2006), por exemplo, propuseram um modelo para a implantação de um Sistema de Gestão Ambiental (SGA) adaptado às Instituições de Ensino Superior que quiserem implantar a sistematização de procedimentos nesse sentido, a partir de um modelo de PDCA (Plan, Do, Control and Act), conforme Figura 1.

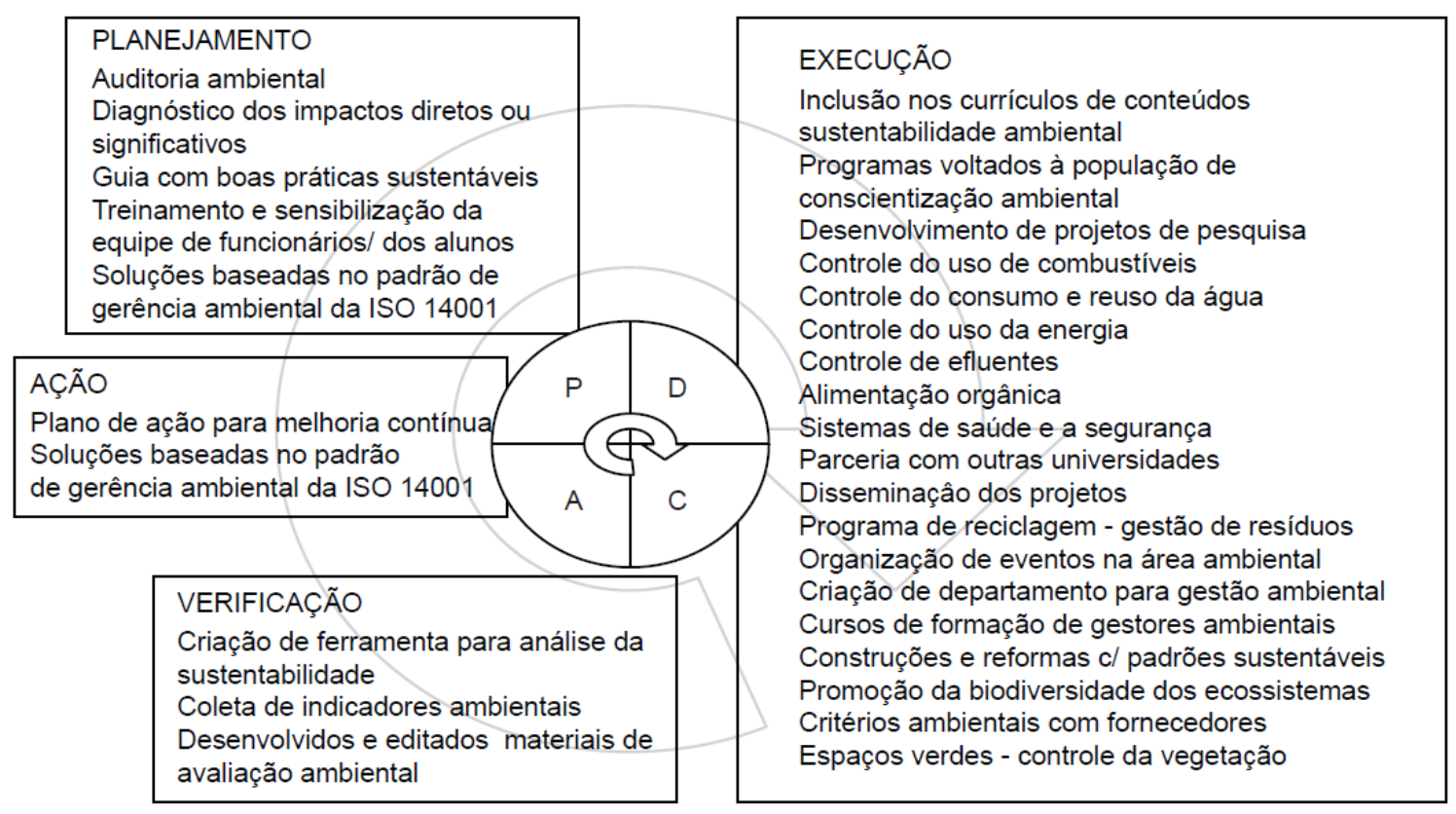

Figura 1 - Modelo PDCA (Fonte: Tauchen e Brandli, 2006)

\subsection{Tecnologia da Informação}

A complexidade de uma Instituição de Ensino, ou de qualquer outro tipo de empresa, principalmente de médio ou grande porte, torna o uso intensivo de Tecnologia da Informação (TI) uma necessidade primária. A TI passa a ter uma condição de facilitadora dos processos empresariais, viabilizando modelos complexos e auxiliando o acesso às informações gerenciais. No tocante das IES, a TI atinge um novo patamar em que começa a influenciar, e quem sabe até revolucionar, o modo de aprendizado dentro e fora das IES.

Serão abordados conceitos de Enterprise Resource Planning (ERP) e Ensino a Distância (EAD). 


\subsubsection{ERP}

O crescimento das organizações ao longo de décadas, assumindo novos níveis de produção, que demandam um controle rígido de suas operações foi acompanhado, e até mesmo promovido, pelo desenvolvimento dos sistemas informatizados. Chou et al (2005) apresenta a década de 60 com sistemas de controle de estoque. Já na década de 70, o conceito de Material Requirement Planning (MRP), ou Planejamento de Necessidades de Materiais, foi sistematizado, apresentando uma evolução com a introdução do planejamento da produção. Na década de 80 , os sistemas passaram a absorver o conceito de Manufacturing Resource Planning (MRP II), ou Planejamento de Recursos da Manufatura, precursor dos ERP atuais. Neles, outras áreas da empresa passavam a se integrar com a produção, inclusive as previsões de demanda futura com a otimização dos processos produtivos. Hoje, os ERP são sistemas globais que atendem todos os tipos de segmentos empresariais, com foco nas transações operacionais das empresas.

A figura 2 demonstra a distribuição das fornecedoras de ERP para pequenas e médias empresas, com relação a "Capacidade de Execução" no eixo Y e a "Abrangência da Visão de Futuro" no eixo X. O quadrante dos Líderes é ocupado pelos players Microsoft e SAP. Os ERP voltados para grandes empresas, devido à sua grande complexidade, tornaram-se pacotes evoluídos internamente nos clientes, gerando um alto grau de customização. Os grandes players voltaram seus desenvolvimentos então para as pequenas e médias empresas, que possuem mais facilidade para adaptar seus processos aos padrões do ERP. 


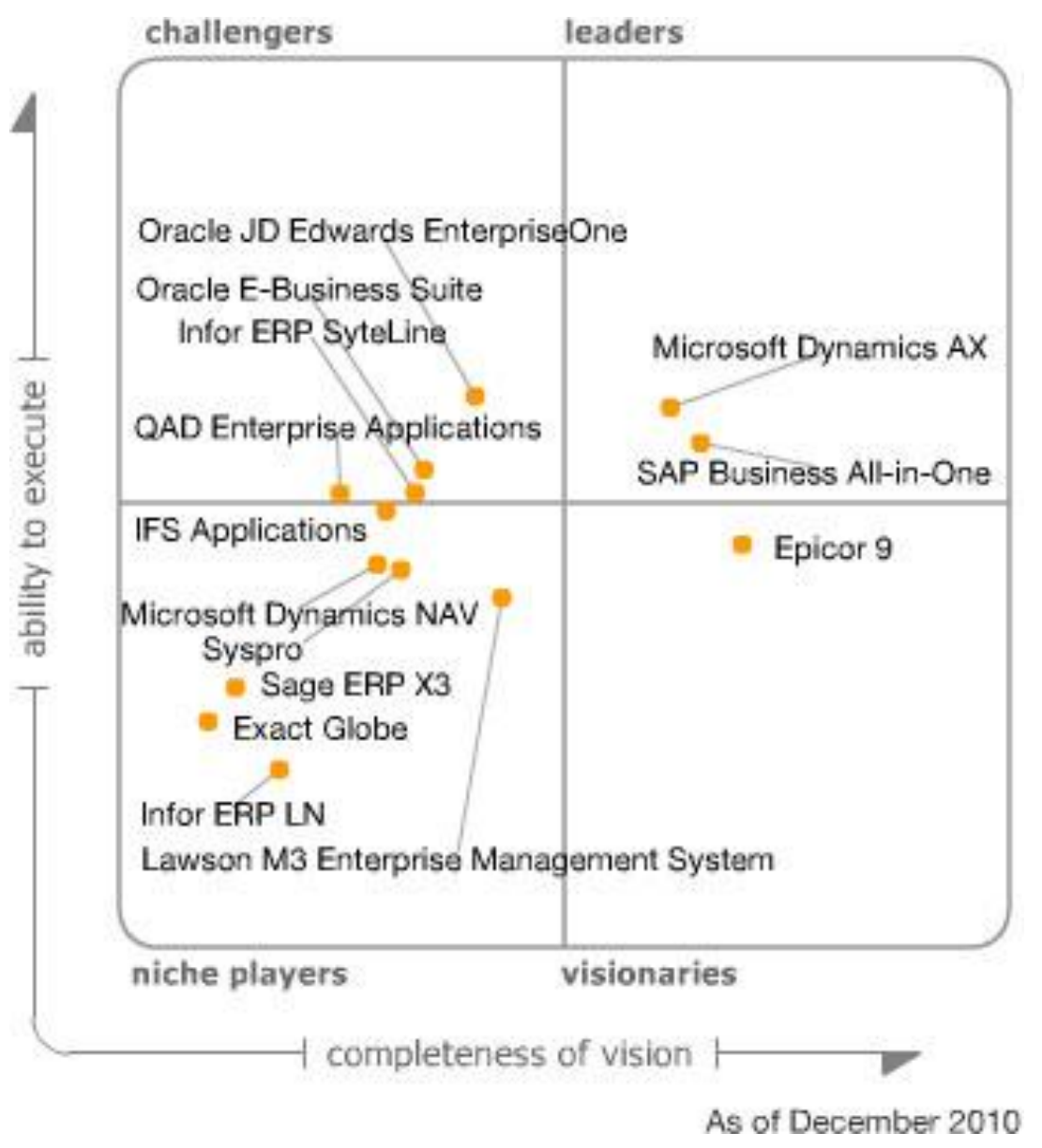

Figura 2 - Fornecedores de ERP (Fonte: Gartner Group, 2012)

As IES, privadas ou públicas, no Brasil utilizam ERP desenvolvidos por fornecedores de pacotes, ou desenvolvidos por uma equipe própria da Instituição (in house), com características únicas de seu segmento, educação. Os chamados ERP Acadêmicos contemplam, além dos processos administrativos, financeiros, de recursos humanos e outros, todos os processos acadêmicos inerentes às IES.

Dávalos e Mulbert (2002) referem-se à implantação do ERP Acadêmico como sendo "a expectativa de disponibilizar informações, fornecer meios para uma integração, diminuir o esforço gerencial e operacional, oferecer transparência e estruturação do planejamento operacional, e apoiar aos processos de gestão universitária".

Nos dias atuais, as informações gerenciais para auxílio à tomada de decisão são de grande importância dentro das organizações. Para atender esta demanda, as fornecedoras de softwares passaram a oferecer módulos extras aos seus ERP com tal finalidade. Esses módulos são chamados de Business Intelligence (BI), que de acordo com Chou et al (2005), é um termo guarda-chuva introduzido em 1989 por 
Howard Dresner, consultor do Gartnet Group, como sendo um conjunto de conceitos e metodologias que auxiliam o acesso a informação gerencial, facilitando a tomada de decisão.

A figura 3 demonstra a distribuição das fornecedoras de BI, com relação a "Capacidade de Execução" no eixo Y e a "Abrangência da Visão de Futuro" no eixo X. O quadrante dos Líderes é ocupado pelos players Microsoft, SAP, SAS, IBM, Oracle e outros. A ausência de um player no quadrante de Visionários indica o amadurecimento do conceito e ferramental de BI.

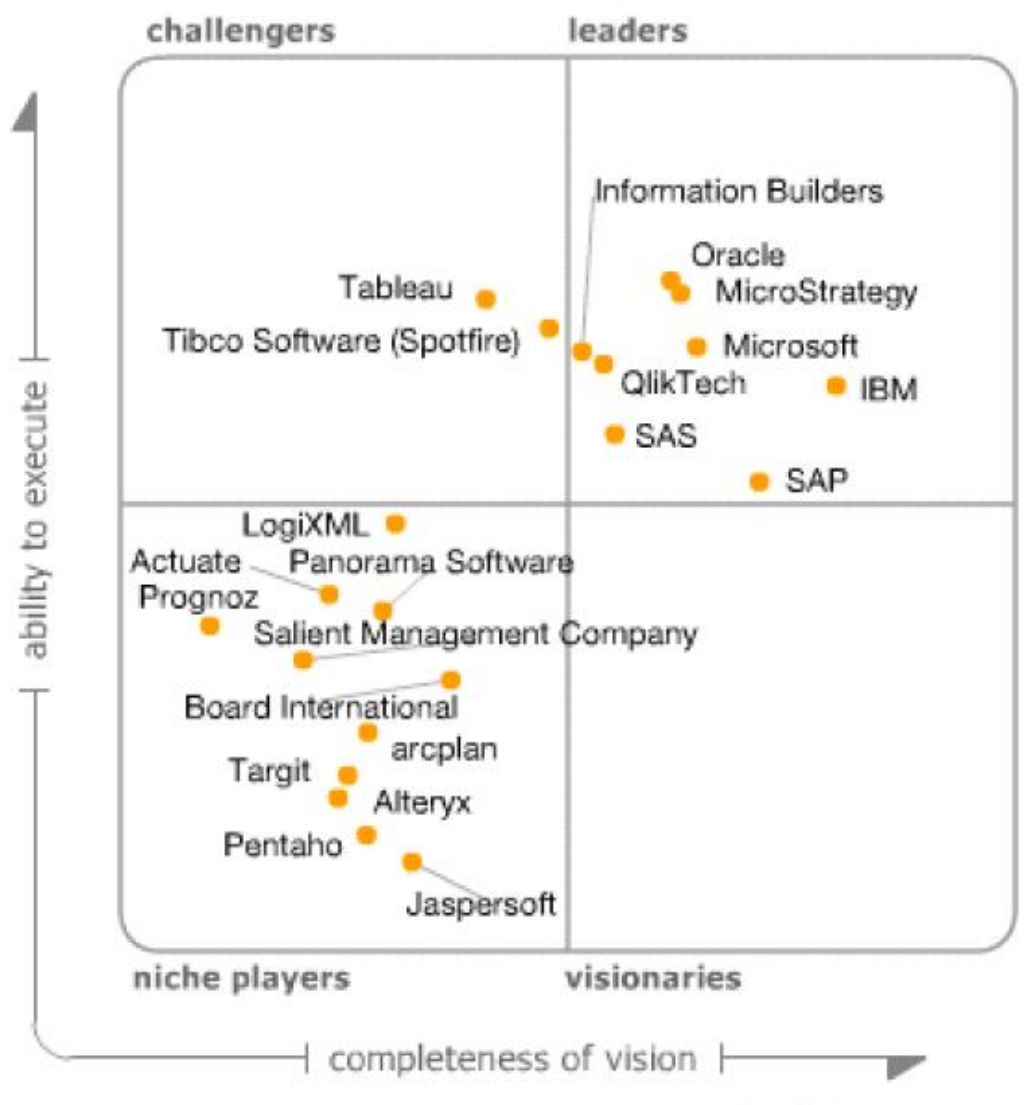

As of February 2012

Figura 3 - Fornecedores de BI (Fonte: Gartner Group, 2012)

\subsubsection{EAD}

A Educação a Distância $(\mathrm{EaD})$ é o novo modelo de ensino, que extrapola os limites físicos de um campus universitário, permitindo a disseminação do conhecimento através do uso de tecnologias avançadas de apresentação e comunicação, que atendem as necessidades didáticas e pedagógicas. 
De acordo com Almeida (2003), o uso de meios de comunicação de massa, como o rádio e a televisão, foram os responsáveis pelo crescimento da $\mathrm{EaD}$, utilizando para isso sistemas de correio para a distribuição das apostilas de acompanhamento, gerando assim um modelo padrão de transferência de conhecimento, igual para todos os alunos.

O Censo da Educação Superior do INEP (2012) apresenta um crescimento acentuado dos programas de Ensino a Distância. No ano de 2010 o Brasil tinha 930 mil alunos de Graduação matriculados, contra 41 mil em 2002. Isso representa um crescimento de mais de $2.100 \%$ em menos de uma década, como pode ser observado na Figura 4.

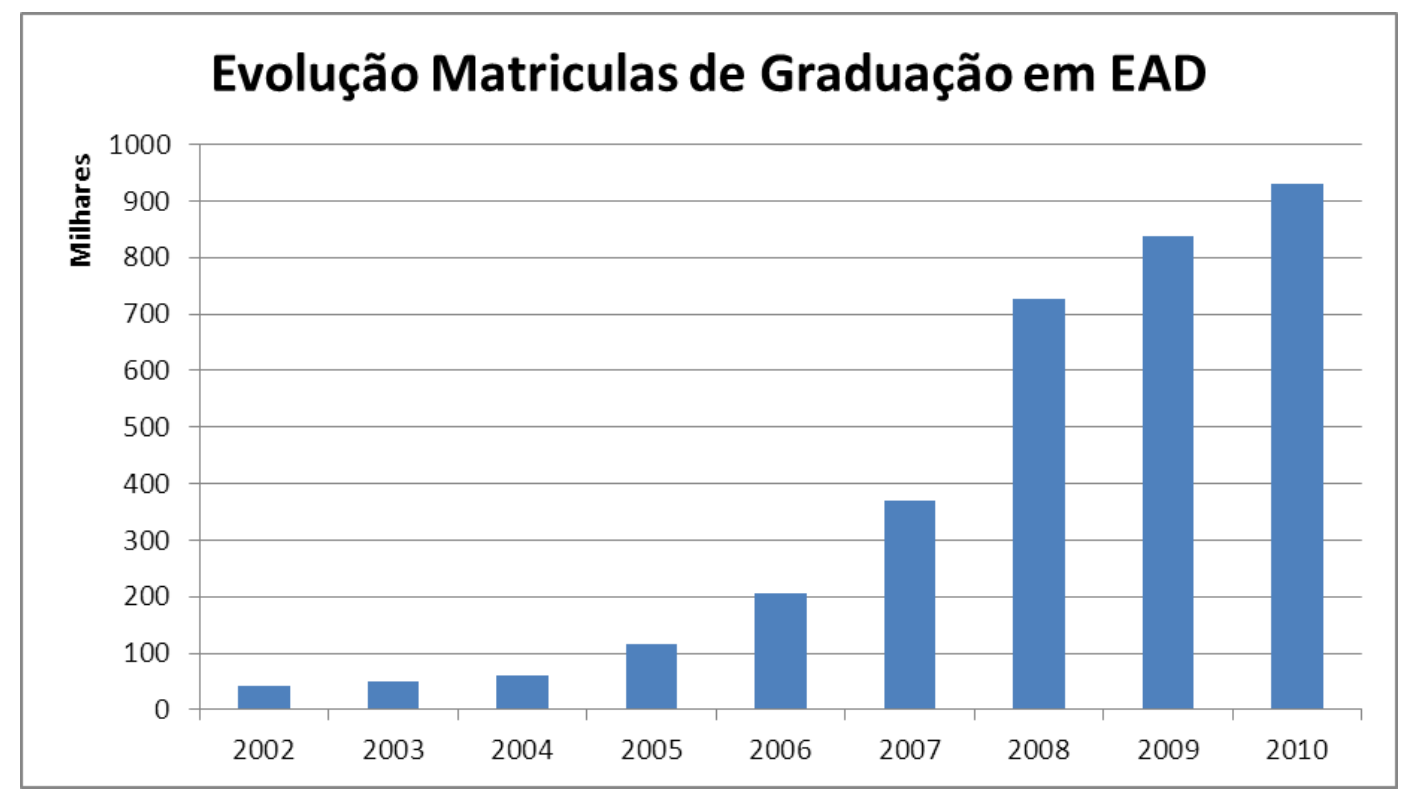

Figura 4- Evolução de Matrículas de Graduação em EAD (Fonte: INEP, 2012)

Almeida (2003) apresenta que as novas tecnologias de informação e comunicação (TIC) renovaram o modelo de $\mathrm{EaD}$, facilitando ainda mais a superação de barreiras de tempo e geográficas, incluindo as disponibilidades de apostilas, permitindo ainda fazer uso do mundo digital e seu potencial de interação.

\subsection{Modelo de Gestão Universitária Baseado em Sustentabilidade}

Com o objetivo de desenvolver um modelo conciso que detalhasse a Gestão Universitária apresentada neste Capítulo, e abrangendo questões ambientais, foram delineados os quatro pilares da Sustentabilidade nos quais este estudo está 
baseado: Excelência em Ensino e Pesquisa, Gestão Financeira, Responsabilidade Social e Responsabilidade Ambiental (vide Figura 5). Vale ressaltar que em quaisquer discussões acerca de desenvolvimento e sustentabilidade, as dimensões ambiental, econômico-financeira e social estão sempre presentes.

\section{Gestão Universitária}

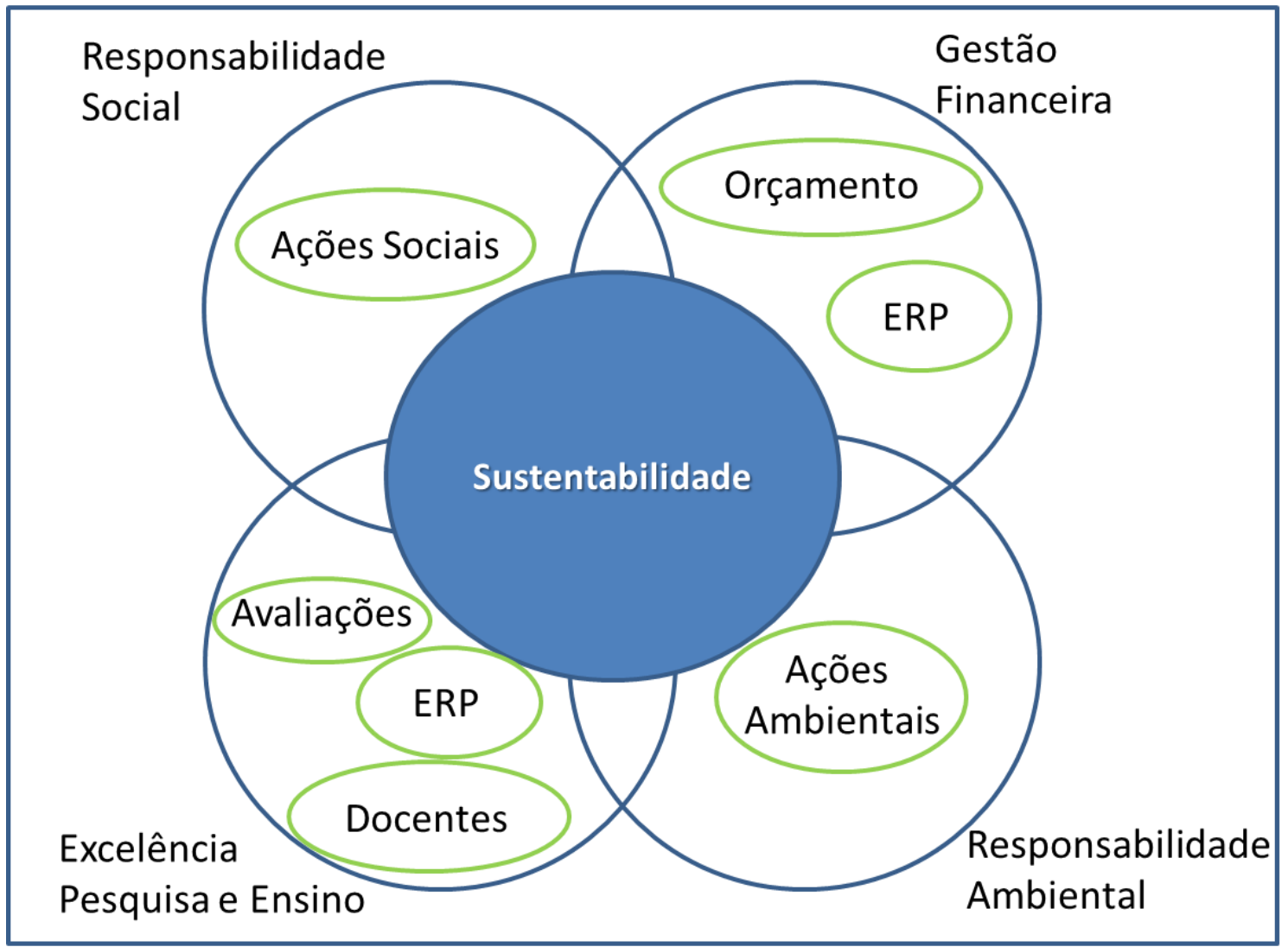

Figura 5 - Modelo Geral da Pesquisa (Fonte: Elaborado pelo autor)

Fonseca (2009) afirma que a definição do significado do termo desenvolvimento sustentável é complexo, já que parte de palavras com sentidos opostos, desenvolver e sustentar. Sendo assim, uma definição específica do termo passa a ser um desafio.

O modelo proposto parte de uma indicação de balanceamento entre os pilares que apoiam a sustentabilidade da Gestão Universitária. Sendo assim, uma IES que se volta para o pilar Financeiro, ou para o pilar de Excelência, terá que mensurar suas necessidades e responsabilidades em atender às demandas dos outros pilares. 


\section{Metodologia}

Este capítulo visa delinear os procedimentos metodológicos e fases da pesquisa realizada para comparar as ações de universidades dentro dos quatro pilares chave desta dissertação: Excelência Acadêmica, Sustentabilidade Financeira, Responsabilidade Social e Responsabilidade Ambiental, perante as estratégias de Sustentabilidade em Gestão Universitária adotadas pela PUC-Rio.

\subsection{Tipo, Estratégia e Método de pesquisa}

Para abranger o maior número de informações possíveis quanto às peculiaridades do tema de estudo, percebeu-se que era preciso trilhar um caminho de teor qualitativo. Assim, quanto à estratégia, essa pesquisa é qualitativa, mesmo utilizando um questionário semi-estruturado. Para as questões mais naturais sobre os quatro pilares desta pesquisa, utilizou-se a escala Likert, mais comumente utilizada em questionários de escalas que vão de "Discordo totalmente" a "Concordo totalmente". Escalas são instrumentos que procuram medir a intensidade das opiniões e atitudes do modo mais objetivo possível. Uma escala consiste na disposição, em forma gradual de itens, pela qual se mede uma característica ou propriedade, de acordo com um número previamente determinado. São compostas por classes, que são as gradações ou escolhas de respostas oferecidas. O que se espera de uma escala é a discriminação de avaliações, de medidas (Gil, 1999). Este mesmo autor afirma que a escala de Likert é de elaboração simples e tem caráter de colocar em ordem, e não mede o quanto uma opinião ou uma atitude é mais ou menos favorável. É uma escala onde os participantes registram sua concordância ou discordância perante um enunciado.

O interesse em abordagens mais qualitativas, segundo Laville e Dionne (1999), tende a conservar mais a forma literal dos dados. Sabia-se desde o início que não se conseguiria uma amostra grande dentro do universo pesquisado.

Assim, a partir desta primeira visão da metodologia, esta pesquisa caracteriza-se principalmente como um estudo de caso, quanto ao método, segundo Yin (2005), focando na análise do caso PUC-Rio para posterior comparação com os resultados da pesquisa do questionário. Este autor, referência 
no assunto, afirma que o estudo de caso visto como estratégia de pesquisa compreende um método que abrange a lógica de planejamento, técnicas de coleta de dados e abordagens peculiares de análise dos mesmos.

Já quanto ao tipo, é de cunho descritivo (Laville e Dionne, 1999), uma vez que não pretende descobrir novas teorias, mas sim comparar os modelos de gestão adotados em universidades na América Latina e Europa com aquele adotado na PUC-Rio, no sentido de avaliar a Gestão Universitária da última.

A pesquisa do estudo de caso PUC-Rio foi realizada através de análise documental e experiência própria do autor desta dissertação. Já para coletar as percepções e atitudes desempenhadas em IES da América Latina e Europa baseadas nos quatro pilares chave desta pesquisa, foram aplicados questionários, como já mencionado.

\subsection{Universo e amostra}

O universo deste estudo é constituído de todas as Instituições de Ensino Superior existentes. A unidade de análise, entretanto, foi composta pelas IES participantes do SUMA - Hacia una Gestión Financiera Sostenible de las Universidades en América Latina, evento escolhido por permitir o encontro de universidades da América Latina e europeias da Espanha, Alemanha, Áustria e Itália - 22 ao todo (SUMA, 2012). A PUC-Rio também participou do evento e a oportunidade e conveniência permitiu a aplicação dos questionários.

Vale ressaltar que o SUMA é um projeto financiado pela Comissão Europeia, pretendendo criar estratégias de conhecimento para permitir a sustentabilidade financeira das universidades participantes, por meio de troca de experiências e melhores práticas.

A amostra foi composta de 11 universidades:

Quadro 1 - Lista de Universidades respondentes do Questionário

\begin{tabular}{|c|c|c|}
\hline Continente & País & Universidade \\
\hline América do Sul & Bolívia & Universidad Mayor de San Francisco Xavier de \\
& & Chuquisaca \\
\hline América do Sul & Chile & Universidad de Viña del Mar \\
\hline América do Sul & Colômbia & Universidad Industrial de Santander \\
\hline América & Costa Rica & Instituto Tecnológico de Costa Rica \\
\hline
\end{tabular}




\begin{tabular}{|c|c|c|}
\hline Continente & País & Universidade \\
\hline Central & & \\
\hline $\begin{array}{c}\text { América } \\
\text { Central }\end{array}$ & El Salvador & Universidad de El Salvador \\
\hline América do Sul & Equador & Universidad Central de Ecuador \\
\hline Europa & Espanha & Universidad de Alicante \\
\hline $\begin{array}{c}\text { América } \\
\text { Central }\end{array}$ & Guatemala & Universidad del Valle de Guatemala \\
\hline $\begin{array}{c}\text { América } \\
\text { Central }\end{array}$ & Honduras & Universidad Nacional Autónoma de Honduras \\
\hline América & Panamá & Universidad Católica Santa María la Antigua \\
Central & & \\
\hline América do Sul & Paraguai & Universidad Nacional del Este \\
\hline
\end{tabular}

Em geral, havia no SUMA dois representantes de cada Universidade participante do encontro. Cada universidade recebeu um questionário para ser preenchido, nos moldes do modelo no Apêndice 1 deste trabalho, no segundo dia do evento. Foi solicitada a resposta até o final do evento.

\subsection{Coleta de Dados}

Primeiramente, foram coletados vários dados secundários por meio de documentos principalmente da instituição caso desta pesquisa, a PUC-Rio. Essa etapa foi primordial para traçar o contexto no qual ocorreria a comparação com outras IES.

Os dados secundários foram analisados e contribuíram para a construção do Caso PUC-Rio. Foram coletados dados de diversas fontes, a fim de montar com veracidade o estudo de caso proposto. Foram utilizadas a Internet (sites da própria PUC-Rio), revistas renomadas no ramo de Gestão Universitária, o sistema de Gestão Universitária da PUC-Rio, além da própria experiência do autor como funcionário da instituição.

Como já mencionado anteriormente, a coleta de dados ocorreu por meio da aplicação de questionários semi-estruturados, aplicados em representantes das IES participantes do IV Taller SUMA Montevideo Uruguay, que ocorreu entre os dias 
15 a 18 de maio de 2012, em Montevidéu, Uruguai, na Universidad Ort.

O projeto SUMA é financiado pela Comissão Europeia, a qual construiu um questionário de Responsabilidade Social para Empresas (Comissão Europeia, 2012), cujos indicadores embasaram várias perguntas do questionário desta dissertação.

Os participantes de 22 países se reuniram para discutir a sustentabilidade financeira nas Instituições de Ensino Superior. Foi solicitada então a todos os 21 outros participantes a resposta do questionário. Ao todo foram coletadas 11 respostas, o que representa mais de $50 \%$ de êxito.

\subsection{Tratamento dos Dados}

A análise documental possibilitou conhecer mais a fundo a realidade da PUC-Rio no que tange às ações práticas quanto à Gestão Universitária. Foram realizadas leituras críticas de documentos importantes da instituição, e a experiência profissional do autor permitiu traçar um panorama da PUC-Rio, contribuindo para o surgimento de sugestões de melhoria contínua do processo.

Com a aplicação dos questionários, foram realizados tratamentos estatísticos básicos, como média, desvio padrão e análises de frequência de respostas. Estas análises permitiram a posterior comparação com a situação atual do caso PUCRio.

Os resultados podem ser verificados no Capítulo 5 desta Dissertação.

\subsection{Fases da Pesquisa}

Este estudo foi dividido em etapas para que se conseguisse organizar os conceitos e chegar aos resultados da melhor maneira possível.

Primeiramente, foi definido o escopo da pesquisa e a delimitação do estudo na área de Gestão Universitária, considerando a relevância do tema e a colocação da PUC-Rio nas melhores posições dos rankings mundiais de universidades.

Posteriormente, os dados secundários foram coletados e, assim, foi definido o conteúdo do Referencial Teórico.

Com os temas definidos dentro do escopo Gestão Universitária, foi construído o Questionário e definida a forma de aplicação e Metodologia. 
Assim, com os dados coletados após a participação no IV Taller SUMA Montevideo Uruguay, foi possível proceder à análise mais aprofundada dos documentos, e às análises qualitativa e quantitativa dos questionários.

Por fim, o estudo de caso PUC-Rio foi apresentado dentro dos quatro pilares chave que norteiam este trabalho, e, com isso, confrontado com os resultados encontrados das outras universidades que responderam à pesquisa.

A partir da comparação anterior foi possível tecer considerações e conclusões sobre comparações da Gestão Universitária atual.

Uma vez que o objetivo desta dissertação é avaliar a Gestão Universitária na PUC-Rio, para o estudo de caso foram delineadas as seguintes fases:

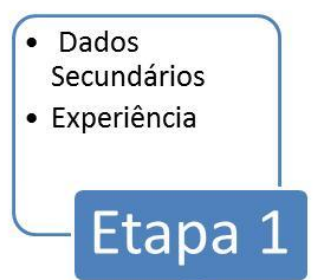

\section{Etapa 2}

- Observações informais

- Anotações

\section{Etapa 1}

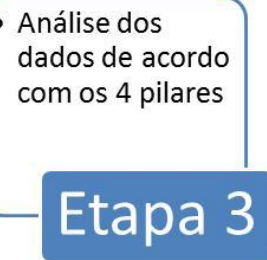

- Análise dos dados de acordo com os 4 pilares

\section{Etapa 3}

Figura 6- Etapas da Pesquisa (Fonte: Elaborado pelo autor)

A Figura 7 mostra o esquema geral das fases da dissertação.

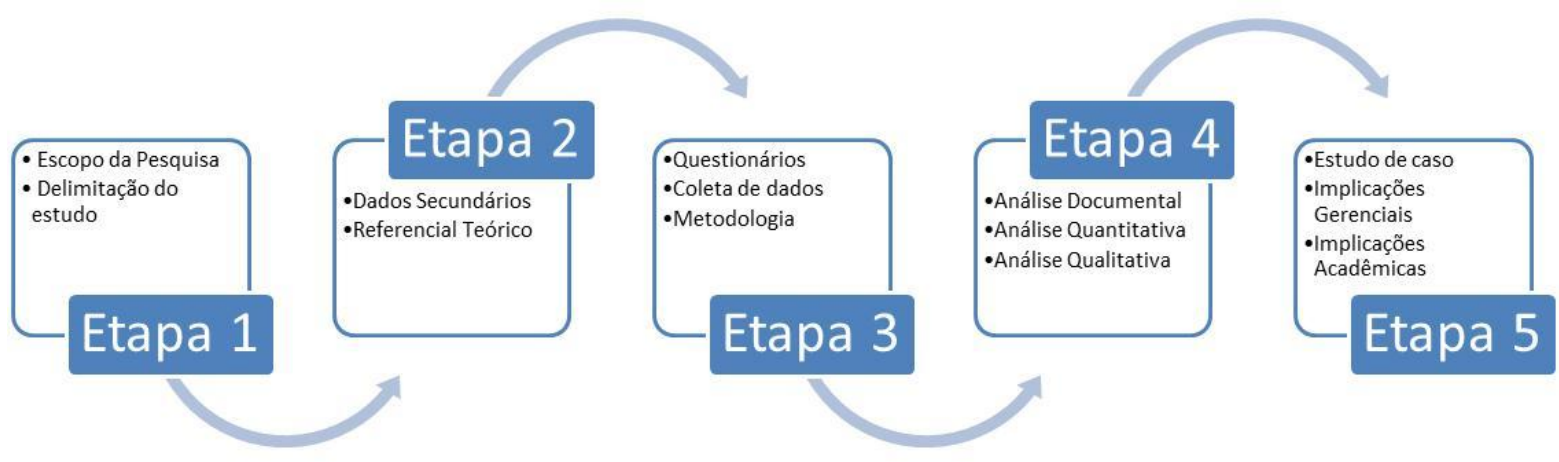

Figura 7- Etapas da Pesquisa (Fonte: Elaborado pelo autor) 


\subsection{Construção do Questionário}

Baseando-se nas pesquisas realizadas sobre os quatro pilares da sustentabilidade na IES, o questionário foi elaborado com indicadores existentes na literatura sobre os temas, levemente adaptados para a realidade encontrada.

Assim, a partir de todo o contexto de avaliação de IES hoje existente, as ações que foram consideradas mais importantes para dimensionar a Excelência em Ensino e Pesquisa foram com relação a(ao):

1) Avaliação de desempenho acadêmico de seus professores;

2) Existência de incubadora de empresas;

3) Inovação e espírito empresarial;

4) Participações da docência em projetos de pesquisa;

5) Participação dos estudantes em projetos de pesquisa;

6) Investimento em aquisições de livros, revistas e bases de dados para a biblioteca;

7) Estrutura de ensino à distância (EAD); $e$

8) Sistema de acompanhamento de egressos.

Já para a Gestão Financeira, os indicadores que mais se mostraram pertinentes para a pesquisa com as IES foram:

1) A universidade estabelece um Planejamento Financeiro, definindo metas de despesas e investimentos para os próximos meses;

2) São realizadas reuniões para comparar os valores planejados $e$ realizados;

3) A universidade identifica as fontes de recursos necessárias para o financiamento da Universidade;

4) A universidade realiza planejamento financeiro de médio e longo prazo;

5) A universidade possui uma estrutura interna de planejamento financeiro e orçamentário;

6) Na sua opinião, quais são os grandes desafios da sustentabilidade financeira para a Universidade. 
Os itens adaptados do Questionário de Sensibilização da Comissão Européia identificados como importantes para a identificação do estágio de comprometimento das IES com a Responsabilidade Social, a partir dos estudos mostrados no Capítulo 2 desta Dissertação foram:

1) A universidade oferece oportunidades de capacitação aos membros da comunidade local (por exemplo, estágios ou oportunidades de emprego para os jovens ou pessoas carentes);

2) Existe um canal aberto de diálogo com a comunidade local sobre as questões desfavoráveis;

3) Seus funcionários são incentivados a participar de atividades com a comunidade local;

4) A universidade oferece apoio financeiro aos projetos com a comunidade local.

Em um contexto mais global, também foram adaptados indicadores utilizados pela área de Responsabilidade Ambiental das Empresas da Comissão Europeia de avaliação de empresas, assim como descrito no item anterior. Buscando-se, em plena globalização, uma uniformização de procedimentos, e se pautando numa visão global de impacto das IES, decidiu-se utilizar esses indicadores:

1) A universidade possui um documento formal dos projetos e ações para a sustentabilidade ambiental;

2) A universidade conta com um setor específico centrado na sustentabilidade ambiental;

3) A universidade tem trabalhado para reduzir o impacto ambiental em termos de:

a. Economia de energia;

b. Minimização e reciclagem de resíduos;

c. Proteção da natureza.

Com relação à Tecnologia da Informação, foram selecionadas questões relativas à estrutura de TI da Gestão Universitária de cada IES, com foco na 
utilização do ERP:

1) A universidade possui um sistema formal de ERP;

2) Caso afirmativo, como foi feito o desenvolvimento do ERP;

3) Qual a faixa percentual que a Universidade dispende na manutenção dos sistemas de TI administrativos e acadêmicos em relação ao gasto total;

4) Quais os módulos que o seu sistema suporta (Matrícula, Bolsas, Faturamento, Avaliação Acadêmica, Gestão de Notas, Indicadores de Desempenho, Gestão Financeira, Gestão Orçamentária, Gestão RH, Outros).

\subsection{Limitações dos Métodos}

Após delinear todo o esquema da pesquisa, é importante salientar que é impossível generalizar resultados encontrados, uma vez que a pesquisa com as Universidades participantes foi realizada com uma amostra, que por si só já é considerada pequena com relação ao universo.

Há também limitações inerentes à aplicação de questionários a uma pequena amostra. Esta foi peculiar, formada de participantes do SUMA, o encontro que formou a conveniência da pesquisa.

Deve-se também considerar que os participantes do encontro eram representantes das universidades que nem sempre obtinham todos os dados necessários à mão.

Além disso, perguntas abertas também podem levar a alto grau de subjetividade de respostas.

A pesquisa foi feita num instante $t$, dando uma visão de curto prazo do cenário da Gestão Universitária.

Com relação ao estudo de caso PUC-Rio, é como se um retrato tivesse sido tirado neste instante $\mathrm{t}$, num corte transversal, mostrando a realidade desta Instituição naquele momento. Importante lembrar que cada tomada de decisão dos seus gestores muda o curso e a evolução da Universidade. 


\section{Caso PUC-Rio}

A Pontifícia Universidade Católica do Rio de Janeiro (PUC-Rio) é representada pela Pessoa Jurídica Faculdades Católicas, a Entidade Mantenedora. É uma Associação sem fins lucrativos.

De acordo com PUC-Rio 70 anos (2010), a Faculdades Católicas teve seu funcionamento autorizado pelo decreto de 30 de outubro de 1940, pelo então Presidente Getúlio Vargas, tendo Padre Leonel Franca, S.J. como o primeiro reitor das Faculdades Católicas, que oferecia os cursos de Direito e Filosofia. As duas faculdades estavam provisoriamente localizadas no Colégio Santo Inácio. Com a criação da Escola de Serviço Social, em 1945, foi constituída a Universidade Católica, reconhecida 1946. Em 1947, a Santa Sé concedeu o título de Universidade Pontifícia. Em 1948 foi fundada a Escola Politécnica, oferecendo cursos de Engenharia. Na década de 50 foram adquiridos os terrenos para a futura sede da PUC-Rio no bairro da Gávea. Em 1955 o campus Gávea foi inaugurado. $\mathrm{Na}$ década de 60 foi instalado o primeiro computador de grande porte com fins acadêmicos em uma IES da América-Latina.

Pelo Estatuto da Entidade Mantenedora (ESTATUTO, 2008), seu objeto é de fundação, administração e manutenção de instituições de educação e estabelecimentos de educação superior que integrem a Pontifícia Universidade Católica do Rio de Janeiro. O Presidente do Conselho Diretor é definido em eleição da Assembleia Geral, a partir de indicação da Associação Nóbrega de Educação e Assistência Social (ANEAS). A Assembleia Geral também tem o papel de nomear os membros do Conselho Fiscal.

Atualmente, a PUC-Rio possui em sua estrutura, o Conselho de Desenvolvimento, o Conselho Universitário e o Conselho de Ensino e Pesquisa. O Reitor da PUC-Rio é indicado pela Companhia de Jesus e nomeado por Sua Excelência o Grão Chanceler da Arquidiocese de São Sebastião do Rio de Janeiro, com mandato de 3 anos, podendo ser renovado.

No organograma da Universidade, conforme figura 8, reportando diretamente ao Reitor e Vice-Reitor, estão presentes 4 Vice-Reitorias (Acadêmica, Administrativa, Comunitária, Desenvolvimento). Abaixo do nível de ViceReitoria, encontra-se os 4 Decanatos de cada área de Ensino (Teologia e Ciências Humanas, Ciências Sociais, Técnico-Científico e Ciências Biológicas e 
Medicina). Dentro de cada Decanato, estão associados os Departamentos Acadêmicos, que são responsáveis pelos diversos cursos de Graduação e PósGraduação da Universidade.

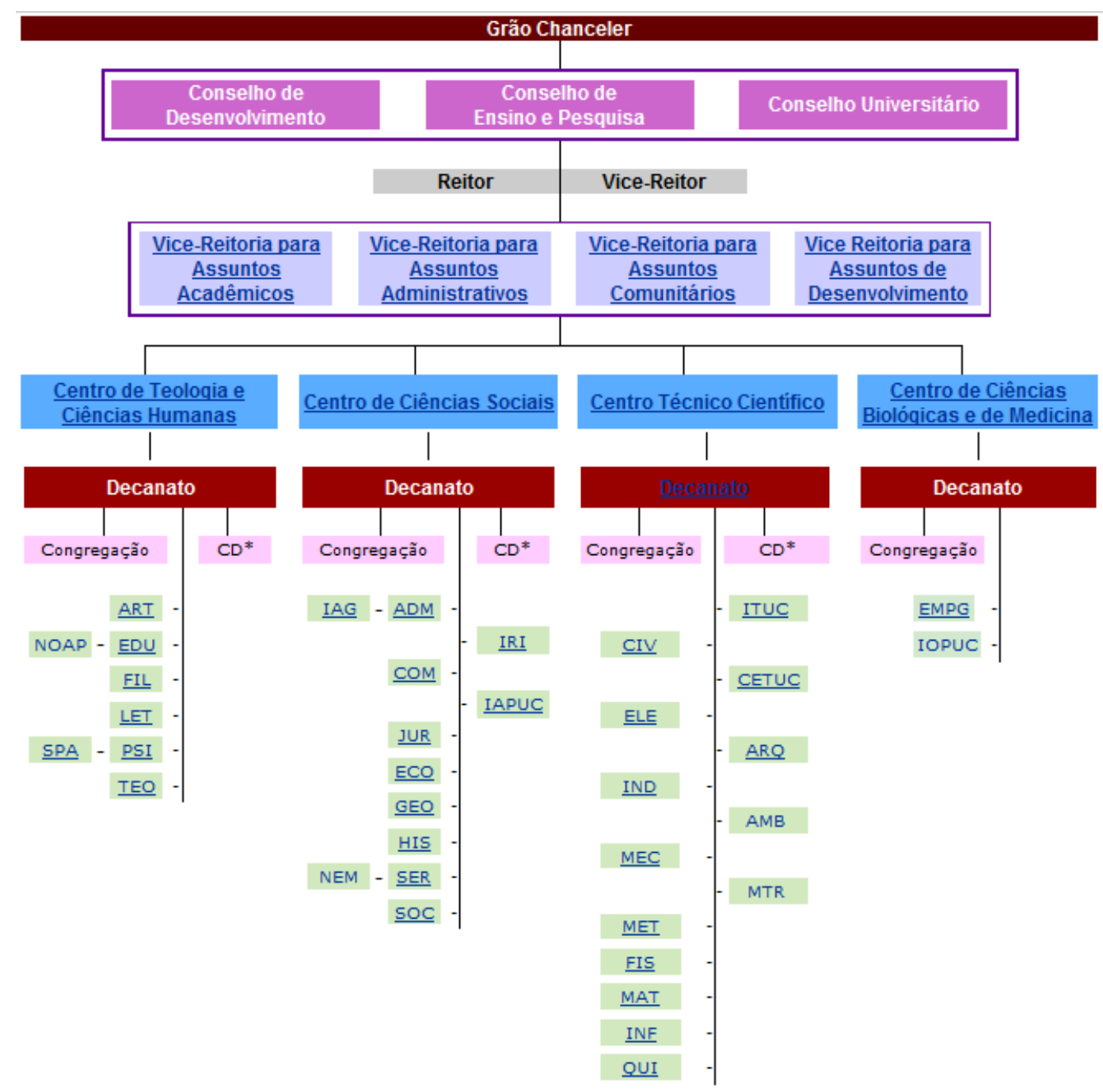

Figura 8 - Organograma da PUC-Rio (Fonte: PUC-Rio, 2012)

A PUC-Rio oferecia, em 2011, 35 cursos de Graduação, 25 cursos de Mestrado, 3 cursos de Mestrado Profissional e 22 cursos de Doutorado. Ao todo, eram 12.928 alunos de Graduação, 2.272 alunos de pós-graduação stricto-sensu e 8.245 alunos de cursos de extensão e especialização.

Seu corpo Docente era composto por 422 Professores do Quadro Principal, 823 Professores do Quadro Complementar e 40 Professores do Quadro Suplementar. Ao todo, eram 788 Professores com titulação de Doutor e 497 com titulação de Mestre.

O desenvolvimento deste Capítulo utilizará a aplicação do modelo da 
Dissertação na realidade da PUC-Rio, identificando componentes da instituição que formam os 4 pilares formadores da Sustentabilidade na Gestão Universitária. Será apresentado cada um desses componentes agrupado por cada pilar, além do grupo de Tecnologia da Informação, que se apresenta como facilitador dos processos institucionais.

\section{Gestão Universitária}

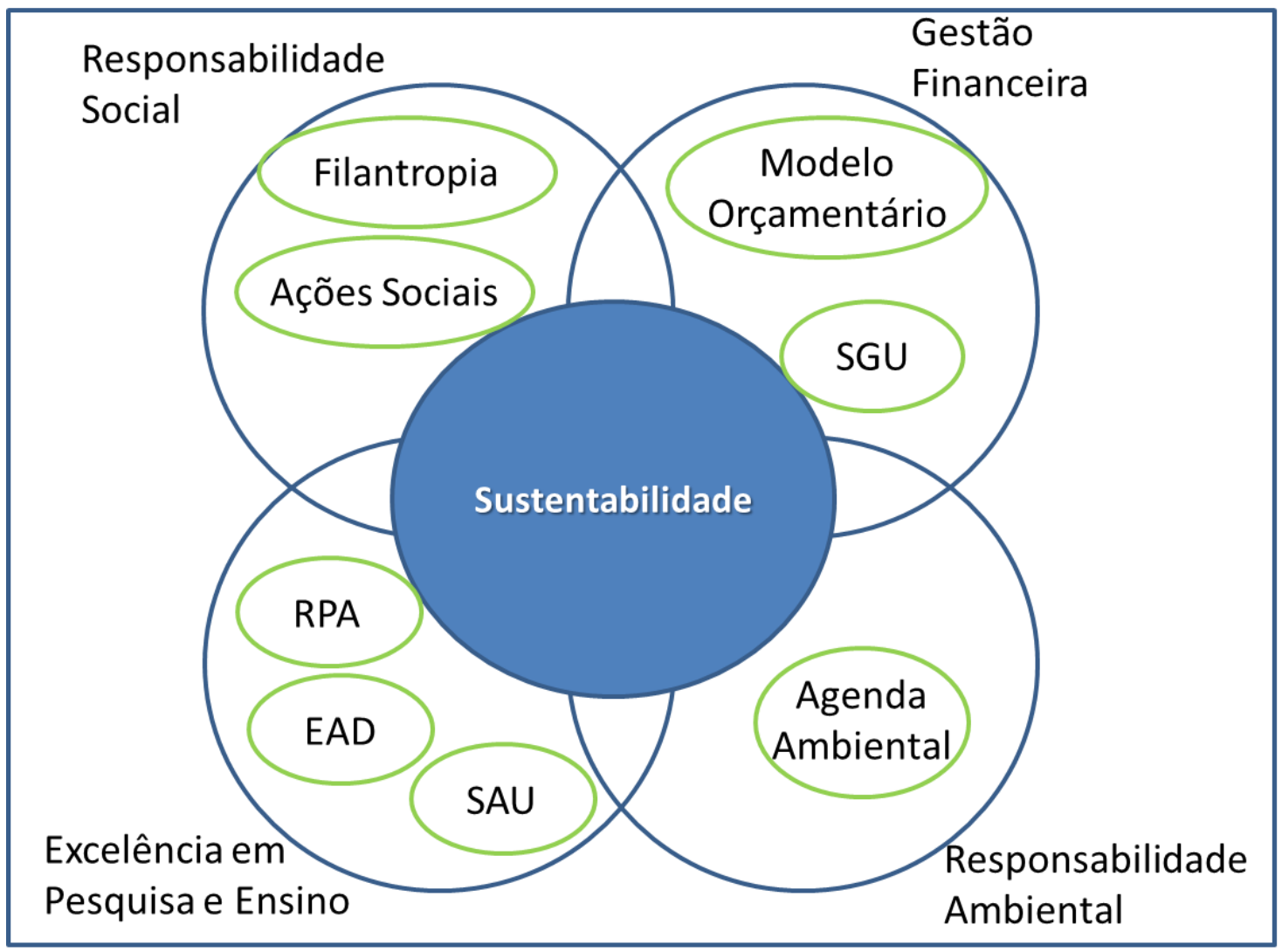

Figura 9 - Modelo Aplicado ao Caso PUC-Rio (Fonte: Elaborado pelo autor)

\subsection{Excelência em Ensino e Pesquisa}

\subsubsection{Planejamento e Avaliação Acadêmica}

O Planejamento e Avaliação Acadêmica na PUC-Rio é de responsabilidade da Coordenação Central de Planejamento e Avaliação (CCPA), que faz parte da Vice-Reitoria Acadêmica.

A CCPA tem a responsabilidade no desenvolvimento do Programa de Avaliação Institucional da PUC-Rio. A partir da elaboração desse documento a CCPA elabora o Plano de Desenvolvimento Institucional (PDI), uma das 
dimensões apresentada no Capítulo 1 do SINAES, sistema de avaliação do INEP.

A Coordenação Central possui ainda a Rede de Perfis Acadêmicos da PUC-Rio (RPA@PUC), que tem como finalidade o controle de toda a produção acadêmica da universidade, fornecendo fácil acesso pela Internet.

\subsubsection{Renovação de Sua Excelência}

Um dos grandes desafios da PUC-Rio é a manutenção de sua excelência. O quadro de seu corpo docente com dedicação exclusiva, que representa a maioria de seus pesquisadores, precisa de um cuidadoso planejamento para, na medida em que se mostre necessário, ser renovado. Com esse objetivo, a PUC-Rio lançou, em 2010, seu Programa de Renovação de Quadros (PRQ), incialmente exclusivo para professores de tempo contínuo, e depois estendido para funcionários técnicoadministrativos. O referido programa oferece benefícios para o caso de adesão de professores e funcionários.

O objetivo de tal programa é fornecer subsídios para a transição da renovação, tornando-a um processo equilibrado ao longo do tempo. Até o momento a renovação mostra-se um sucesso, com resultados significativos atingidos pelos novos professores (contribuição acadêmica).

\subsection{Gestão Financeira}

\subsubsection{Evolução do Modelo de Financiamento}

Até o fim da década de 80, todo o Centro Técnico Científico, o Departamento de Economia e o Rio Data Centro (RDC) eram custeados com recursos da Financiadora de Estudos e Projetos (FINEP). Após o rompimento do convênio pela FINEP, a PUC-Rio viu sua folha de pagamento e seu custeio aumentarem significativamente, passando por dificuldades financeiras, além de greves de professores e funcionários.

$\mathrm{Na}$ década de 90, iniciou-se, portanto, um crescimento no número de alunos da Instituição, auxiliando a equalização das receitas e despesas. Nesse período, a PUC-Rio passou da ordem de 7.500 alunos de Graduação para 13.000 em 2012, um aumento de 73\%. O grande desafio era de um crescimento 
sustentável, que não afetasse a qualidade no Ensino e Pesquisa.

No início dos anos 2000, a PUC-Rio começou a viver um momento de grande crescimento em Projetos de Pesquisa, apoiados por agências de fomento, por exemplo, a FINEP, e empresas estatais, principalmente a PETROBRAS. Os recursos oriundos desses projetos, e os ressarcimentos de despesas administrativas e operacionais incorridas pela execução dos mesmos dentro da Instituição, passam a ter destaque dentro das finanças. Hoje, a falta de percepção dos concedentes de recursos para projetos de que despesas indiretas, e muitas vezes indivisíveis, são onerosas para a Universidade, torna muita vezes um Projeto deficitário financeiramente, tendo a PUC-Rio que custeá-lo, objetivando um superávit acadêmico. Discussões entre representantes da PUC-Rio e dos órgãos concedentes tentam demonstrar que a PUC-Rio situa-se em um raro modelo de ser uma Instituição Privada fortemente ativa na Pesquisa, precisando assim, ser avaliada de forma realista em seus custos de administração de projetos.

\subsubsection{Modelo Orçamentário}

Com o início da implantação do ERP Administrativo na PUC-Rio, foi elaborado um modelo orçamentário que mesclava as características privadas da instituição em conjunto com conhecimentos da orçamentação pública da equipe desenvolvedora. Essa junção tornou-se extremamente interessante para o Caso PUC devido às características de Pesquisa financiadas por órgãos de fomento público. Sendo assim, o acompanhamento orçamentário-financeiro das unidades acadêmicas, unidades de apoio e Projetos de Pesquisa foram influenciados pelo modelo público.

O modelo orçamentário PUC, assim como qualquer outro modelo orçamentário, aborda as fases de Planejamento, Execução e Controle. A PUC-Rio, devido à necessidade de flexibilidade e agilidade em decisões focais, possui um alto grau de descentralização de poderes para a execução orçamentária.

Anualmente, as unidades acadêmicas e de apoio realizam, com base nos seus gastos no ano e com perspectivas para o ano seguinte, o planejamento de seu orçamento para o exercício seguinte, divido por rubricas de gastos. A solicitação é analisada pela Coordenação Central de Orçamento, que determina o valor a ser dotado para cada unidade. 
A partir da dotação, o sistema ERP provisiona mensalmente os valores destinados a cada unidade, a partir de uma distribuição mensal pré-estabelecida.

Esse planejamento tem como objetivo fornecer subsídios para o Funcionamento e Manutenção das diversas unidades, não compreendendo, portanto, os Projetos de Pesquisa. São consideradas despesas de Funcionamento e Manutenção as que atendem o custeio das unidades, como material de consumo e pequenos serviços de reparos.

Além do Funcionamento e Manutenção, as Despesas Corporativas são planejadas pelas unidades de apoio, como Prefeitura do Campus, Superintendência Administrativa, Assessoria Jurídica e Superintendência de Recursos Humanos. Entretanto, não existem provisões orçamentárias para tais despesas, visto que são inerentes de seu funcionamento e, portanto, obrigatórias. $\mathrm{O}$ orçamento possui como dever acompanhar esses gastos e verificar a correta aplicação dos recursos, sem desvios, já que as execuções das Despesas Corporativas são de responsabilidade da unidade a que o gasto se refere. São consideradas Despesas Corporativas os custos de energia, seguro, água, telefone, benefícios de pessoal vinculado, assessoria jurídica externa, entre outros.

O Orçamento possui três tipos de fonte de recursos. A primeira, e a base para o funcionamento da Instituição, é a chamada Fonte PUC. Essa se refere basicamente às receitas de mensalidades. Existe também a Fonte de Contratos, que se refere aos recursos de contratos de Pesquisa, custeados em grande parte por empresas privadas ou de economia mista. A terceira é a Fonte de Convênio, que se refere exclusivamente a convênios administrativos de Pesquisa com órgãos governamentais, como Ministérios, Secretarias e FINEP. Hoje a PETROBRAS firma Termos de Cooperação com a Instituição com recursos oriundos do Fundo de Participação Especial, que a Agência Nacional do Petróleo (ANP) determina a aplicação de percentual da receita da empresa em projetos de Pesquisa e Desenvolvimento (P\&D) com centros externos.

A PUC-Rio partiu de um modelo em que possuía mais de 200 contascorrentes bancárias, que pagavam taxas e que, inevitavelmente, permaneciam períodos deficitárias e pagadoras de juros, para um modelo em que possui, com exceção dos Convênios de Pesquisa, 2 contas, maximizando os processos operacionais da Gerência Financeira e as aplicações financeiras, já que a agregação dos valores gera um poder de negociação mais forte junto às 
instituições bancárias.

Toda a estrutura orçamentária é baseada em Metas Orçamentárias. A Meta é uma ferramenta orçamentária que possui um propósito a ser atingindo, sendo assim o controle financeiro, e até mesmo físico, de um determinado objetivo. $\mathrm{Na}$ prática, são contas correntes virtuais administradas pelo ERP, que recebem créditos orçamentário oriundos de provisões estabelecidas na etapa de planejamento, ou remanejamentos orçamentários de outras Metas, essas podendo ser da própria unidade ou de demais, com prestação de serviços internos ou crédito extra-orçamentário definido pela Administração Central.

Cada Meta orçamentária está relacionada diretamente a uma Fonte de Recursos. As metas de Funcionamento e Manutenção das unidades são exclusivas da Fonte PUC. Cada contrato de Pesquisa possui uma Meta relacionada à Fonte de Contratos, e o mesmo ocorre para as Metas de Convênios, relacionadas diretamente a uma Fonte de Convênio.

\subsection{Tecnologia da Informação}

\subsubsection{ERP - SGU e SAU}

A PUC-Rio possui dois sistemas desenvolvidos por equipes distintas, que integrados formam o ERP Educacional da Instituição. A parte administrativafinanceira é de responsabilidade do Sistema de Gerência Universitária (SGU) e a parte acadêmica, de responsabilidade do Sistema Acadêmico Universitário (SAU).

No início dos anos 2000, com a necessidade de substituir o sistema administrativo-financeiro até então utilizado, a Administração Central da PUCRio optou por, ao invés de comprar um pacote de um fornecedor do mercado de ERP, desenvolver seu próprio Sistema, com a formação de uma equipe de analistas de sistemas e programadores. Essa opção possibilitou uma grande flexibilidade no desenvolvimento do Sistema, com integração entre diferentes módulos e aperfeiçoamentos de processos administrativo-financeiros.

Hoje o SGU contempla os seguintes módulos:

- Contas a pagar;

- Contas a receber; 
- Fluxo de caixa;

- Emissão de NFe;

- Orçamento;

- Contabilidade;

- Patrimônio;

- Folha de Pagamento;

- Movimentação Funcional Eletrônica;

- Folha de Ponto;

- Segurança e Medicina do Trabalho;

- Controle de Projetos de Pesquisa;

- Controle de Contratos Jurídicos;

- Business Intelligence;

- Portal Corporativo da Vice-Reitoria Administrativa;

- Outros.

A integração entre os diversos módulos é total, gerando grande agilidade nos processos e economia de recursos, seja de pessoas, seja de papel. Como exemplo, uma alteração de carga-horária de um Professor Horista é solicitada via SGU, tendo sua tramitação aprovada eletronicamente pelas diversas instâncias (Departamento, Coordenação de Graduação, Vice-Reitoria Acadêmica) que resulta na alteração imediata de seu salário na Folha de Pagamento, que por sua vez dispara através do Contas a Pagar, o depósito do valor na conta bancária do Professor.

O SAU é também um Sistema desenvolvido in house, tendo sua história iniciada com os primeiros computadores de grande porte do Rio Data Centro. O Sistema tem como módulos:

- Gestão da Matrícula;

- Gerenciamento das Notas;

- Outros.

A base de dados utilizada, tanto do SAU quanto do SGU, é o banco de dados IBM DB2, tendo como vantagem o compartilhamento de mesma 
tecnologia, o que possibilidade uma facilidade na integração de informações.

O SGU, para seus módulos de Business Intelligence e Portal Corporativo, utiliza produtos Microsoft, fazendo uso do contrato de Campus Agreement estabelecido entre a fornecedora de software e a Instituição, que gera redução drástica nos valores dispendidos com software.

\subsubsection{EaD -CCEAD}

A PUC-Rio, no que se refere ao Ensino a Distância $(\mathrm{EaD})$, possui a Coordenação Central de Educação a Distância (CCEAD), ligada à Vice-Reitoria Acadêmica. A CCEAD oferece cursos de extensão, especialização, graduação e apoio aos cursos presenciais. Fundada em 1999, foi credenciada pelo Ministério da Educação (MEC) em 2004 para oferecer cursos de Pós-Graduação lato sensu a distância, tendo o credenciamento para Graduação em 2005.

Durante toda sua existência, a CCEAD recebeu diversos prêmios pelo trabalho desenvolvido, como o Prêmio e-Learning Brasil 2007. A Coordenação Central possui diversos projetos com órgãos federais, como o caso do Fundo Nacional de Desenvolvimento da Educação, com o convênio de Tecnologias em Educação.

\subsection{Responsabilidade Social}

\subsubsection{Assistência Social - Filantropia}

A PUC-Rio é uma entidade sem fins lucrativos, detentora do Certificado de Entidade Beneficente de Assistência Social. Por ser uma entidade sem fins lucrativos é, garantida pela Constituição Federal, imune aos impostos da esfera federal, estadual e municipal. Ela atende aos requisitos da Lei 12.101/09 da Filantropia e da Lei 11.096/05 do PROUNI, o que significa que está isenta do pagamento da cota patronal previdenciária. Essa é a contrapartida oferecida pelo Governo pelo trabalho social desenvolvido pela Instituição. Ao atender as leis citadas, a PUC-Rio oferece $20 \%$ de suas receitas de mensalidade efetivamente recebidas em Bolsas de Estudo para jovens carentes, cuja renda per capita familiar não ultrapasse 1,5 salário mínimo para bolsas de $100 \%$ e 3 salários mínimos para 
bolsas de $50 \%$.

A PUC-Rio oferece, aos jovens que comprovam limitações financeiras, subsídios para auxiliar a sua manutenção dentro do campus universitário. A própria localização geográfica da PUC-Rio se torna uma barreira significativa no que se refere a transporte da moradia até a universidade, a alimentação durante o período letivo, o acesso a livros acadêmicos e outros. Existem políticas sociais desenvolvidas pela Universidade com auxílio de outras entidades privadas e agências de fomento.

O Fundo Emergencial de Solidariedade da PUC-Rio (FESP) fornece auxílio transporte, alimentação, moradia e material didático, buscando a manutenção dos alunos bolsistas em seus cursos de graduação. Os próprios Professores e Funcionários da PUC-Rio auxiliam o FESP com doações realizadas diretamente de seus contracheques, além dos recursos oriundos da Associação Nóbrega de Educação e Assistência (ANEAS).

O projeto Protagonismo Universitário e Empoderamento Profissional (PROUNIR), financiado pela Secretaria Especial de Políticas de Promoção da Igualdade Racial - SEPPIR, da Presidência da República, forneceu condições de acesso ao material didático pedagógico e a cultura para alunos bolsistas.

\subsection{Responsabilidade Ambiental}

\subsubsection{Agenda Ambiental PUC-Rio}

Assumindo seu papel diante da sociedade e na formação de seus alunos, a PUC-Rio instituiu em 2009 a Agenda Ambiental da PUC-Rio. Coordenado pelo Núcleo Interdisciplinar de Meio Ambiente (NIMA), o documento demonstra a vocação ambiental da Instituição, e tem como objetivo inserir práticas que permitam e estimulem a responsabilidade ambiental no Campus, assumindo princípios humanitários, científicos e éticos.

A Agenda Ambiental é divida nos seguintes tópicos:

- Biodiversidade;

- Água;

- Energia; 
- Atmosfera;

- Materiais;

- Resíduos;

- Educação Ambiental.

Para cada tópico, o documento possui o posicionamento ético ambiental da PUC-Rio, as diretrizes que definem o caminho a ser seguido dentro do tema, e mais importante, metas de curto, médio e longo prazo a serem atingidas pela Instituição. 


\section{Avaliação das universidades da América Latina e Europa}

Com o objetivo de avaliar a situação da PUC-Rio frente às outras Universidades pelo mundo, foi realizada uma pesquisa com 11 Universidades, com elevada importância nacional e reconhecimento internacional, de 11 diferentes países da América Latina e Europa.

O questionário foi baseado no Modelo PUC-Rio apresentado a todos os respondentes que foi demonstrado na Delimitação do Estudo, no capítulo 1.

Dentro das 4 grandes estruturas, Excelência em Ensino e Pesquisa, Gestão Financeira, Responsabilidade Ambiental e Responsabilidade Social, foram elaboradas perguntas associadas, com o objetivo de avaliar tais questões, incluindo ainda o grupo de Tecnologias da Informação como o facilitador pontos abordados.

Após a definição dos questionários válidos para a análise, foram realizadas estatísticas básicas das respostas.

Em cada estrutura de análise, serão apresentados os valores de média, desvio padrão, mínimos e máximos de cada resposta, lembrando que em grande parte das perguntas foi utilizada a escala Likert, de 1 a 5, sendo 3 interpretado como neutro.

\subsection{Excelência em Ensino e Pesquisa}

A pergunta com a menor média apresentada é a "A Universidade possui uma Incubadora de Empresas?", demonstrando assim uma baixa importância para a geração de conhecimento a partir de atitudes empreendedoras. Entretanto, o desvio padrão de 1,72 (o maior apresentado em toda a pesquisa) demonstra que a presença de uma Incubadora é realidade em parte dos respondentes, com considerável estrutura de organização. A quarta menor média corrobora essa situação, pertencente à pergunta "A Universidade possui uma unidade de inovação e empreendedorismo?", que apresenta também um valor alto de desvio padrão.

São dados importantes ainda a baixa média para as perguntas "A universidade possui uma estrutura de Ensino à Distância?” e “A universidade possui um sistema de acompanhamento dos egressos?", ambas com médias 
próximas e com importância crescente dentro de um mercado cada vez mais competitivo e disposto a fazer uso de novos tecnologias para captarem novos alunos.

Já a pergunta com a maior média foi "A Universidade possui um Grupo de Avaliação do desempenho acadêmico de seus Professores?”. Isso demonstra uma grande preocupação das instituições com o acompanhamento da qualidade acadêmica de seus Docentes, que resultarão na qualidade acadêmica de cada instituição, ressaltando ainda que o valor mínimo apresentado foi 3.

O quadro abaixo apresenta uma síntese estatística das perguntas do questionário referentes à Excelência em Ensino e Pesquisa.

Tabela 1- Síntese Estatística de Excelência em Ensino e Pesquisa

\begin{tabular}{|c|c|c|c|c|c|}
\hline Num & $\mathbf{N}$ & MÉDIA & DESV.PAD. & MIN & MÁX \\
\hline $\begin{array}{l}\text { Q11) A Universidade possui um } \\
\text { Grupo de Avaliação do } \\
\text { desempenho acadêmico de seus } \\
\text { Professores. }\end{array}$ & 11 & 4,27 & 0,79 & 3 & 5 \\
\hline $\begin{array}{l}\text { Q12) A Universidade possui uma } \\
\text { Empresa Júnior. }\end{array}$ & 11 & 2,82 & 1,72 & 1 & 5 \\
\hline $\begin{array}{l}\text { Q13) A Universidade possui uma } \\
\text { unidade de inovação e } \\
\text { empreendedorismo. }\end{array}$ & 11 & 3,36 & 1,36 & 1 & 5 \\
\hline $\begin{array}{l}\text { Q14) Os professores participam } \\
\text { de Projetos de Pesquisa. }\end{array}$ & 11 & 3,73 & 1,10 & 2 & 5 \\
\hline $\begin{array}{l}\text { Q15) Os alunos participam de } \\
\text { Projetos de Pesquisa. }\end{array}$ & 11 & 3,64 & 1,12 & 2 & 5 \\
\hline $\begin{array}{l}\text { Q16) A Universidade investe na } \\
\text { aquisiçãao de livros, periódicos e } \\
\text { base de dados para sua biblioteca. }\end{array}$ & 11 & 4,09 & 0,94 & 2 & 5 \\
\hline $\begin{array}{l}\text { Q17) A Universidade possui uma } \\
\text { estrutura de Ensino à Distância } \\
\text { (EAD). }\end{array}$ & 11 & 2,91 & 1,64 & 1 & 5 \\
\hline $\begin{array}{l}\text { Q18) A Universidade possui um } \\
\text { sistema de acompanhamento de } \\
\text { egressos. }\end{array}$ & 11 & 3,00 & 1,34 & 1 & 5 \\
\hline
\end{tabular}

Na pergunta aberta "Na sua opinião, quais são os investimentos necessários para a manutenção da excelência acadêmica na sua Universidade?”, a maioria dos respondentes indicaram o investimento na capacitação e formação do corpo Docente e o investimento em novas tecnologias como os principais pontos. 


\subsection{Gestão Financeira}

Foi possível observar que a pergunta com a menor média é "São realizadas reuniões para comparar os valores planejados e executados do orçamento?", demonstrando assim uma baixa importância para a acuricidade do planejamento orçamentário. Podemos considerar um foco no planejamento, tendo a etapa de acompanhamento do ciclo orçamentário demonstrado-se ainda imatura na maior parte das instituições.

Já as perguntas com a maior média foram "A universidade identifica as fontes de recursos necessárias para o financiamento da Universidade?" e "A universidade possui uma estrutura interna de planejamento financeiro e orçamentário?”. Isso demonstra um enraizamento do conceito de Planejamento Financeiro, e sua necessidade para o pleno funcionando das instituições de ensino.

É possível observar uma elevada média em todas as perguntas, o que demonstra um estágio maduro nas instituições no que se refere ao Planejamento Financeiro, característico da grande maioria das Instituições entrevistas, já que temos valores baixos de desvio padrão para esse grupo.

O quadro abaixo apresenta uma síntese estatística das perguntas do questionário referentes à Gestão Financeira.

Tabela 2- Síntese Estatística de Gestão Financeira

\begin{tabular}{|c|c|c|c|c|c|}
\hline Num & $\mathbf{N}$ & MÉDIA & DESV.PAD. & MIN & MÁX \\
\hline $\begin{array}{l}\text { Q21) A universidade estabelece } \\
\text { um Planejamento Financeiro, } \\
\text { definindo metas de despesas e } \\
\text { investimentos para os próximos } \\
\text { meses. }\end{array}$ & 11 & 4,46 & 0,69 & 3 & 5 \\
\hline $\begin{array}{l}\text { Q22) São realizadas reuniões } \\
\text { para comparar os valores } \\
\text { planejados e realizados. }\end{array}$ & 11 & 3,73 & 1,27 & 1 & 5 \\
\hline $\begin{array}{l}\text { Q23) A universidade identifica } \\
\text { as fontes de recursos necessárias } \\
\text { para o financiamento da } \\
\text { Universidade. }\end{array}$ & 11 & 4,55 & 0,52 & 4 & 5 \\
\hline $\begin{array}{l}\text { Q24) A universidade realiza } \\
\text { planejamento financeiro de } \\
\text { médio e longo prazo. }\end{array}$ & 11 & 4,09 & 1,04 & 2 & 5 \\
\hline $\begin{array}{l}\text { Q25) A universidade possui uma } \\
\text { estrutura interna de planejamento } \\
\text { financeiro e orçamentário. }\end{array}$ & 11 & 4,55 & 0,52 & 4 & 5 \\
\hline
\end{tabular}


$\mathrm{Na}$ pergunta aberta "Na sua opinião, quais são os grandes desafios da sustentabilidade financeira para a Universidade?“", a maior parte das respostas envolveram a questão de diversificação das fontes de financiamento, principalmente diminuindo o peso dos fundos estatais; e o desenvolvimento de projetos de pesquisa e programas acadêmicos que ajudem na captação de recursos. A questão de aumentar a remuneração dos Docentes para ser mais competitivo com a contratação de Docentes de qualidade também foi abordada.

\subsection{Tecnologia da Informação}

Para as perguntas do Grupo de Tecnologia da Informação, não foi utilizada a escala Likert. Com isso, a análise parte de estatísticas de frequência.

A questão "A universidade possui um sistema formal de ERP?" obteve 45\% de Sim entre os respondentes. Este é um baixo percentual frente à importância e relevância da informatização, automatização e integração possível com a utilização de um ERP. O baixo percentual pode ser explicado pela presença de Universidades com orçamentos anuais limitados, de países economicamente menores. Tais características dificultam a aquisição ou desenvolvimento de um sistema ERP, optando-se por programas específicos para cada finalidade, de fabricantes muitas vezes regionais.

A pergunta "Caso afirmativo, como foi feito o desenvolvimento do ERP?" apresentou a seguinte distribuição: "In house" com 3 respondentes, "Pacote de Terceiros com Desenvolvimento" com 2 respondentes e "Pacote de Terceiros" sem respondente.

Chama a atenção o fato de $100 \%$ das instituições que possuem ERP, apresentam algum tipo de desenvolvimento próprio, sendo a maioria (60\% do total de respondentes) com desenvolvimento In house. As caracterísitcas peculiares de uma Instituição de Ensino Superior, principalmente no que se refere às Informações Acadêmicas, são limitadores para a aquisição de Pacote de Terceiros, frente à maior oferta para empresas não-acadêmicas.

A pergunta seguinte, "Qual a faixa percentual que a Universidade dispende na manutenção dos sistemas de TI administrativos e acadêmicos em relação ao gasto total da Universidade?" demonstra o baixo orçamento disponibilizado para os sistemas de TI administrativos. 
Gráfico 1 - Manutenção sistemas de TI

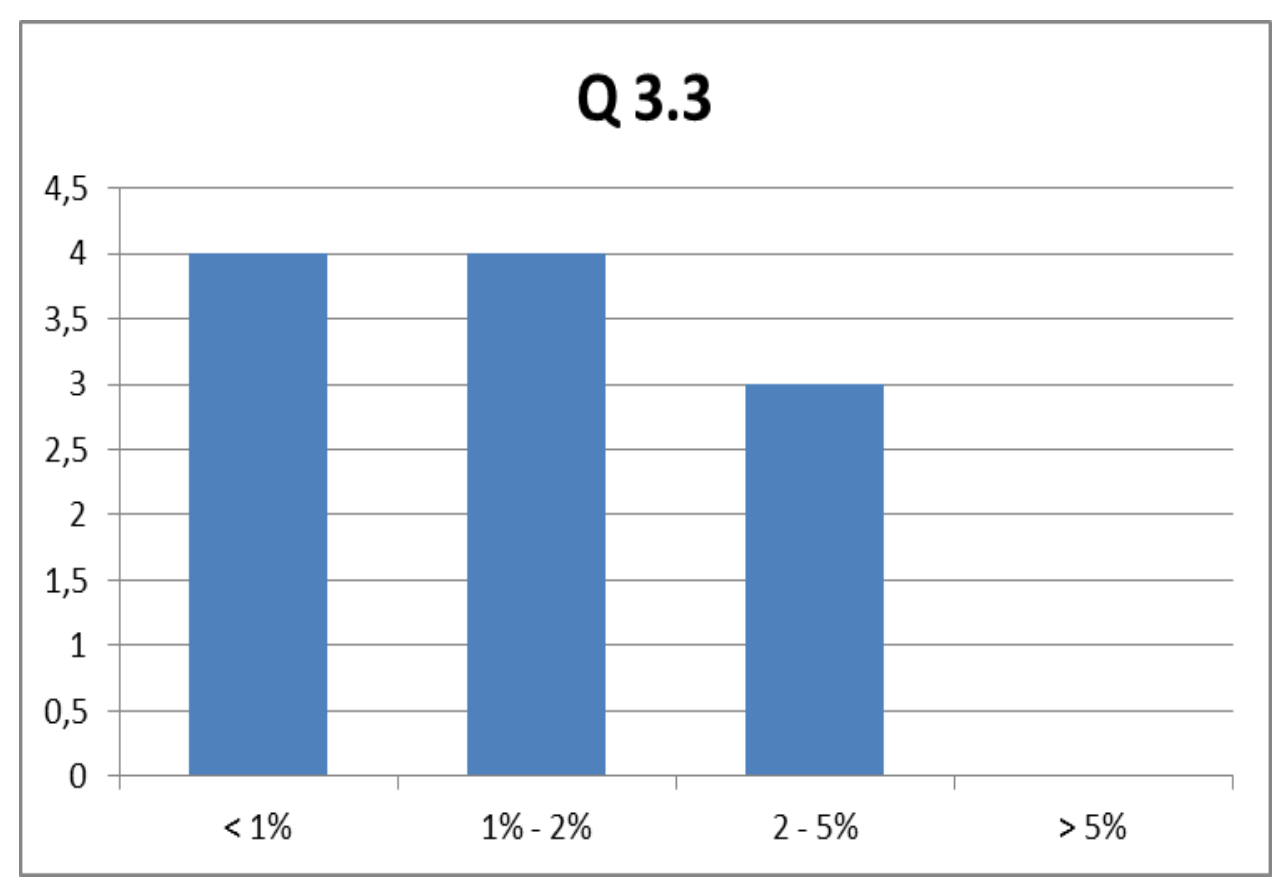

Todavia é importante ressaltar que a média de orçamento das Instituições que possuem ERP (média 2) é superior das que não possuem (média 1,83), o que se mostra coerente devido a própria estrutura de software, hardware e capital humano para a manutenção desses sistemas.

A questão "Por favor, identifique com um "X" todos os módulos que o seu sistema suporta:”, permite a identificação dos principais módulos utilizados por todas as instituições, não apenas aquelas que possuem ERP, mas incluindo também as que possuem sistemas isolados. 
Gráfico 2 - Módulos Suportados

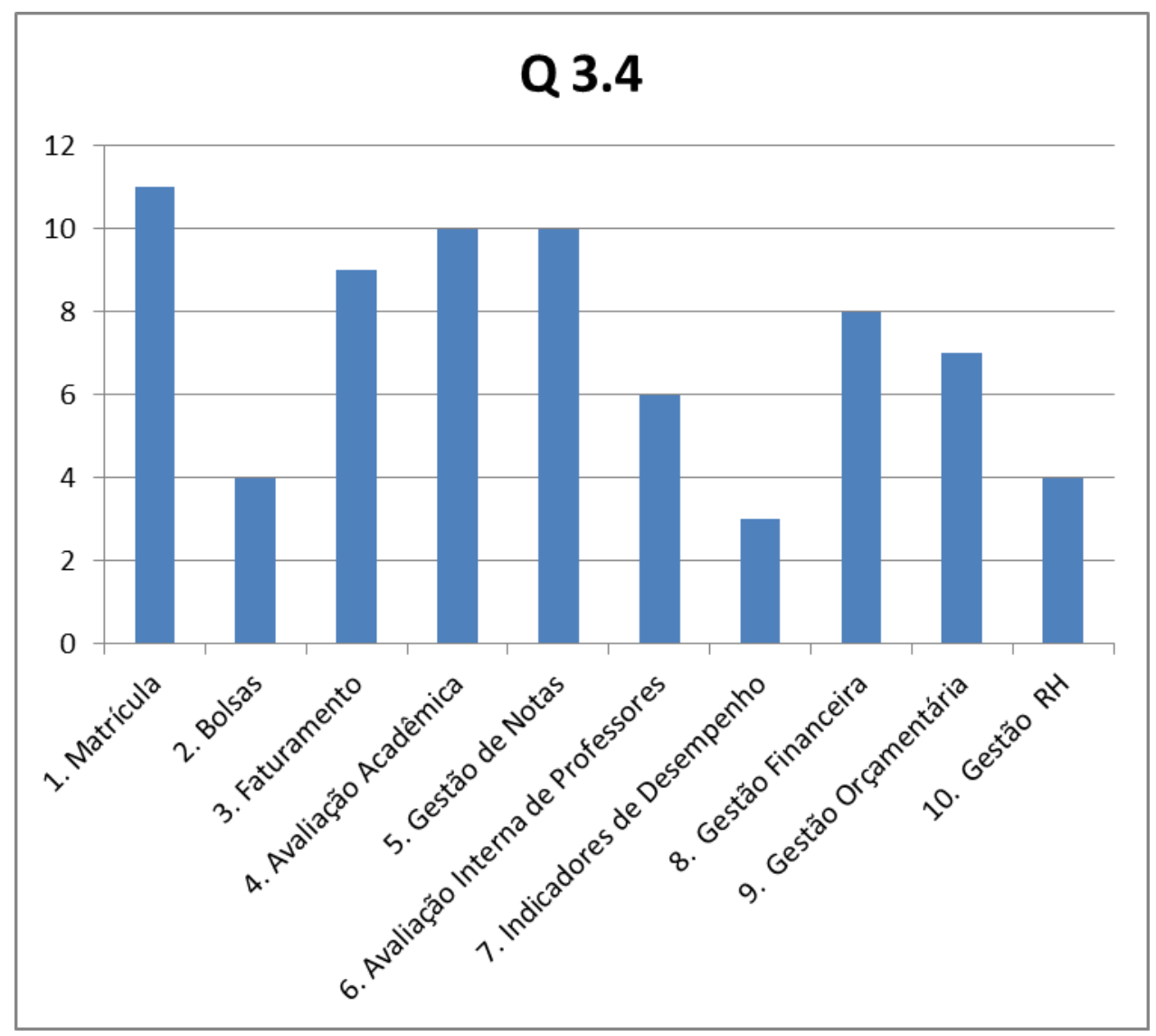

O módulo crucial para uma Instituição de Ensino Superior (IES), e atendido em $100 \%$ das Instituições pesquisadas, é a Matrícula. O controle e alocação dos alunos em períodos, cursos e turmas é questão básica e totalmente atendida. Podemos observar que os outros itens com maior frequência são também relativos às Informações Acadêmicas, como Avaliação Acadêmica e Gestão de Notas, ambos atendidos em 90,9\% das Instituições. Chama a atenção a baixa frequência do item Gestão de Recursos Humanos (RH), onde apenas 36,4\% das IES possuem módulos em seus sistemas de Tecnologia da Informação (TI), o que torna as atividades de RH, como admissão e registro de professores e funcionários, além do próprio pagamento de toda a Folha, tarefas complexas sem o auxílio de sistemas.

\subsection{Responsabilidade Social}

As respostas para o Grupo Responsabilidade Social apresentaram, em média, os maiores valores de desvio padrão, com $75 \%$ das perguntas abaixo de 3 
(neutro). Apresenta também os menores valores médios entre todos os Grupos de perguntas.

A pergunta "A universidade proporciona oportunidades de formação a mebros da comunidade local (como, por exemplo, estágios ou oportunidades de trabalho para jovens ou pessoas pertencentes a grupos desfavorecidos)" foi a com maior média $(3,90)$, demonstrando uma preocupação com o ambiente local em que as Universidades atuam.

Entretanto, as questões "Os seus funcionários são incentivados a participar de atividades com a comunidade local?" e "A universidade oferece apoio financeiro para projetos com a comunidade local?" indica a baixa promoção e efetividade no que se refere às intenções de ajudade ao desenvolvimento de seu ambiente local.

O quadro abaixo apresenta uma síntese estatística das perguntas do questionário referentes à Responsabilidade Social.

Tabela 3- Síntese Estatística de Responsabilidade Social

\begin{tabular}{|c|c|c|c|c|c|}
\hline Num & N & MÉDIA & DESV.PAD. & MIN & MÁX \\
\hline $\begin{array}{c}\text { Q51) A universidade proporciona oportunidades } \\
\text { de formação a mebros da comunidade local } \\
\text { (como, por exemplo, estágios ou oportunidades } \\
\text { de trabalho para jovens ou pessoas pertencentes } \\
\text { a grupos desfavorecidos). }\end{array}$ & $\mathbf{1 1}$ & 3,90 & 1,04 & 2 & 5 \\
\hline $\begin{array}{c}\text { Q52) Dispõe de um canal aberto de diálogo com } \\
\text { a comunidade local sobre questões } \\
\text { desfavoráveis. }\end{array}$ & $\mathbf{1 1}$ & 2,90 & 1,70 & 1 & 5 \\
\hline $\begin{array}{c}\text { Q53) Os seus funcionários são incentivados a } \\
\text { participar de atividades com a comunidade } \\
\text { local. }\end{array}$ & & & & & \\
\hline $\begin{array}{c}\text { Q54) A universidade oferece apoio financeiro } \\
\text { para projetos com a comunidade local. }\end{array}$ & $\mathbf{1 1}$ & 2,82 & 1,47 & 1 & 5 \\
\hline
\end{tabular}

\subsection{Responsabilidade Ambiental}

O Grupo de Responsabilidade Ambiental apresentou valores mais altos de desvio padrão, com seus valores de média próximos ao valor 3 (neutro).

As ações para Economia de Energia e Reciclagem são as que apresentaram as maiores médias $(3,64)$, demonstrando ações para a redução de impacto ambiental das IES. Entretanto, as perguntas "A universidade possui documento formal de projetos e ações voltadas para a sustentabilidade ambiental?" e "A 
universidade possui um setor específico voltado para a sustentabilidade ambiental?" foram as que apresentaram as menores médias, indicando a falta de Planejamento institucional para as questões ambientais.

O quadro a seguir apresenta uma síntese estatística das perguntas do questionário referentes à Responsabilidade Ambiental.

Tabela 4- Síntese Estatística de Responsabilidade Ambiental

\begin{tabular}{|c|c|c|c|c|c|}
\hline Num & $\mathbf{N}$ & MÉDIA & DESV.PAD. & MIN & MÁX \\
\hline $\begin{array}{l}\text { Q41) A universidade possui documento formal de } \\
\text { projetos e ações voltadas para a sustentabilidade } \\
\text { ambiental. }\end{array}$ & 11 & 3,18 & 1,60 & 1 & 5 \\
\hline $\begin{array}{l}\text { Q42) A universidade possui um setor específico } \\
\text { voltado para a sustentabilidade ambiental. }\end{array}$ & 11 & 3,09 & 1,51 & 1 & 5 \\
\hline $\begin{array}{l}\text { Q431) A Universidade já tentou reduzir o impacto } \\
\text { ambiental da sua universidade em termos de economia } \\
\text { de energia }\end{array}$ & 11 & 3,64 & 1,29 & 2 & 5 \\
\hline $\begin{array}{l}\text { Q432) A Universidade já tentou reduzir o impacto } \\
\text { ambiental da sua universidade em termos de } \\
\text { minimização e reciclagem de resíduos. }\end{array}$ & 11 & 3,64 & 1,12 & 2 & 5 \\
\hline $\begin{array}{l}\text { Q433) A Universidade já tentou reduzir o impacto } \\
\text { ambiental da sua universidade em termos de proteção } \\
\text { da Natureza. }\end{array}$ & 11 & 3,55 & 1,21 & 2 & 5 \\
\hline
\end{tabular}




\section{Análise dos Resultados}

Neste capítulo, serão apresentadas análises da realidade da PUC-Rio frente às questões respondidas pelas 11 Instituições de Ensino Superior da América Latina e Europa.

Serão analisadas as relações por grupos, de forma idêntica ao apresentado no capítulo anterior, além de uma análise das melhores práticas das universidades.

\subsection{Excelência em Ensino e Pesquisa}

Como apresentado no Capítulo 1, a PUC-Rio possui reconhecimento nacional e internacional de sua Excelência Acadêmica. Em comparação às instituições pesquisadas, apresenta desempenhos significativos nos quesitos avaliados. Para a primeira e terceira menores médias apresentadas pelos questionários, que se remetem à Incubadora de Empresas, Inovação e Empreendedorismo, a PUC-Rio apresenta unidades específicas, sendo o Instituto Gênesis (IG - Incubadora de Empresas), Agência de Inovação da PUC-Rio (AGI), Empresa Júnior e a Coordenação de Empreendedorismo, fortemente ligada ao IG.

Além disso, possui a Coordenação Central de Ensino a Distância (CCEAD), que vem ao longo dos anos conquistando reconhecimento nacional pelos resultados apresentados com programas de extensão, pós-graduação e um premiado programa de Licenciatura em História para professores de Escolas Públicas. A pergunta do questionário aplicado relativa ao EaD mostrou-se a segunda menor média.

As questões relativas à participação efetiva de professores e estudantes em Projetos de Pesquisa também demonstram uma diferença grande entre a média das Instituições Pesquisadas e a PUC-Rio. No cenário atual, a PUC-Rio possui cerca de $50 \%$ de suas receitas relativas aos Projetos de Pesquisa, com forte envolvimento de seus Professores com dedicação exclusiva, e alunos da Graduação, Mestrado e Doutorado.

Entretanto, assim como a maior parte das Instituições pesquisadas, a PUCRio não possui um sistema de acompanhamento de egresso bem desenvolvido, perdendo assim uma ótima oportunidade de reaproximar os alunos formados para a Universidade. Essa ligação estreita poderia render frutos no que se refere a 
doações de ex-alunos, compartilhamento de experiências bem sucedidas e fortalecimento da marca PUC-Rio no mercado empregador. A Associação de Antigos Alunos da PUC-Rio (AAA/PUC-Rio) tem investido na intenção de ocupar essa lacuna dentro da Instituição.

Com relação às maiores demandas de investimento para a Excelência em Ensino e Pesquisa das Universidades respondentes da pesquisa, a PUC-Rio preocupa-se constantemente com a formação e capacitação de seus professores, como apresentado no Capítulo 4, em que mais de $60 \%$ do quadro possui titulação de Doutor. Além de investimentos em novas tecnologias, tanto de infraestrutura de rede e sistemas, quanto de ensino, através do CCEAD.

A Universidad Industrial de Santander, da Colômbia, é a que apresentou a maior média em todas as perguntas do grupo. Os únicos indicadores em que ela não apresenta "Concordo Totalmente" são atingidos plenamente pela PUC-Rio, que seriam a "A Universidade possui uma unidade de inovação e empreendedorismo?" e "Os alunos participam de Projetos de Pesquisa?"

\subsection{Gestão Financeira}

A PUC-Rio passa por um momento positivo de sua estabilidade financeira, fruto de constantes investimentos no planejamento e controle. Por ser um quesito essencial para a viabilização do funcionamento de qualquer Instituição, um bom desempenho nos indicadores do questionário foi apresentado pelas Universidades pesquisadas.

A questão com menor média, que se refere ao acompanhamento entre o Realizado e Planejado, é de grande importância dentro da PUC-Rio, sendo esse documento analisado e aprovado 4 vezes ao ano pelo Conselho Fiscal e Conselho Diretor da instituição. Devido ao longo tempo desenvolvendo o planejamento orçamentário, a PUC-Rio possui hoje uma elevada acurácia em suas previsões, fruto também de uma série histórica com bom comportamento.

Uma das maiores médias apresentadas nos resultados do questionário aplicado refere-se à identificação de Fontes de Recursos, demonstrando a preocupação das instituições com o assunto. Fica ainda mais explícita essa necessidade na questão aberta em que foram perguntados os desafios da Gestão Financeira, em que a maior parte citou a necessidade da diversificação das fontes 
de financiamento para fomentar pesquisas, fato em que a PUC-Rio avançou fortemente desde o início deste século, com o desenvolvimento de inúmeros projetos de pesquisa com agências de fomento, empresas estatais e privadas.

Os projetos de pesquisa realizados pela PUC-Rio geram retorno acadêmico e financeiro para a PUC-Rio e para seus pesquisadores, atendendo assim as demandas indicadas pelas Universidades respondentes no que diz respeito tanto à diversificação de fontes de financiamento quanto à possibilidade de aumentar a competitividade salarial na permanência e contratação de novos Docentes.

A Universidad de Santander, da Colômbia, é a que apresentou a maior média de respostas do questionário, com "Concordo Totalmente" em todos os indicadores de Gestão Financeira, demonstrando inclusive planejamento financeiro de médio e longo prazo, item não atendido plenamente pela PUC-Rio.

\subsection{Tecnologia da Informação}

As Universidades respondentes do questionário da Pesquisa possuem, em média, limitações no que diz respeito aos sistemas de ERP. Como abordado no Capítulo 5, questões financeiras e tecnológicas de algumas Instituições explicam tais limitações.

A PUC-Rio possui um grande leque de sistemas formadores de seu ERP, atendendo as mais diversas áreas da Universidade. Sendo assim, atividades operacionais acadêmicas, administrativas, financeiras, de recursos humanos e gerenciais são atendidas plenamente.

Um ponto negativo da estrutura adotada é identificado na descentralização da TI dentro da própria Universidade. O sistema administrativo está ligado à ViceReitoria Administrativa, e formado por uma equipe exclusiva. Já a parte acadêmica possui outras duas equipes ligadas à Vice-Reitoria Acadêmica, uma focada no Planejamento e Avaliação Acadêmica, e outra no sistema acadêmico de matrícula e nota da Instituição. Nesse sentido, existe um overlap de funções e recursos, diminuindo a integração dos sistemas e a sinergia possível.

A Universidad de Alicante, da Espanha, é a que apresentou o maior orçamento percentual em relação aos gastos totais para o desenvolvimento de sistemas de TI. Além disso, apresentou seu ERP com bom atendimento de módulos, não atendendo apenas demandas de Controle de Bolsas e de Avaliação 
Interna de Professores, módulos que o SGU, o ERP administrativo da PUC-Rio atende plenamente.

\subsection{Responsabilidade Social}

As baixas médias observadas nas questões do grupo de Responsabilidade Social contrastam com a realidade da PUC-Rio. A preocupação com sua função social é uma das características mais marcantes da Universidade. Além das bolsas que são de responsabilidade legal (Entidade Beneficente de Assistência Social), inúmeras outras bolsas são distribuídas e ações sociais efetivas são realizadas.

Apesar de incentivar, a PUC-Rio deveria promover de forma mais clara a participação de seus funcionários em projetos de auxílio à comunidade carente. A disponibilização de recursos financeiros e de infraestrutura é realizada pela Universidade, mas o maior envolvimento do corpo de funcionários e professores poderia gerar resultados motivadores para a PUC-Rio e para a comunidade local.

A Universidad de Santander, da Colômbia, é a que apresentou a maior média de respostas do questionário. $\mathrm{O}$ único indicador não atendido plenamente pela Universidade é "Os seus funcionários são incentivados a participar de atividades com a comunidade local?”, questão em que a PUC-Rio também deveria promover ainda mais entre seu quadro de funcionários.

\subsection{Responsabilidade Ambiental}

A avaliação das respostas do questionário da Pesquisa sobre Responsabilidade Ambiental também indica médias baixas para as questões.

$\mathrm{O}$ grande destaque que a PUC-Rio apresenta em relação às outras Universidades pesquisadas é relacionado com as duas perguntas de menor média apresentada. A PUC-Rio possui um documento formal (Agenda Ambiental) que trata de seu direcionamento no que tange a questão ambiental, e também possui um setor específico voltado para o Meio Ambiente, que é o Núcleo Interdisciplinar de Meio Ambiente (NIMA).

O foco na questão ambiental é corroborado pelo papel desempenhado pela Universidade nos debates científicos que antecedeu o evento RIO+20. Palco de diversas discussões e apresentações, o campus da PUC-Rio recebeu inúmeros 
pesquisadores, técnicos e políticos com o objetivo de aprofundar conhecimentos e experiências entre toda a comunidade, na expectativa de gerar resultados tangíveis para toda a sociedade. Os seus funcionários são incentivados a participar de atividades com a comunidade local.

A Universidad de Santander, da Colômbia, mais uma vez, é a que apresentou a maior média de respostas do questionário, assinalando "Concordo Totalmente" em todos os indicadores do grupo de Responsabilidade Ambiental.

\subsection{Avaliação das Melhores Práticas}

A Universidade de Alicante, na Espanha, possui uma estrutura de gestão universitária que atende às demandas de uma instituição com mais de 28.000 alunos, 39 cursos de graduação e 91 de pós-graduação.

É possível observar na pesquisa que, principalmente para os pilares de Gestão Financeira, Excelência em Ensino e Pesquisa e Responsabilidade Ambiental, além do grupo de Tecnologia da Informação (TI), a Universidade de Alicante mostra-se consolidada. Apresenta, portanto, focos na avaliação de desempenho acadêmico, incubadora de empresas, investimentos em biblioteca e inovação. Sua Gestão Financeira atende plenamente os objetivos de planejamento de médio e longo prazo, definição de metas investimento, além da preocupação na diversificação das fontes de financiamento. O suporte de TI para a Universidade é realizado por um sistema de Enterprise Resource Planning (ERP) desenvolvido internamente e com considerável destinação de recursos para a sua manutenção e aprimoramento, que atende inúmeras atividades administrativas e acadêmicas da Instituição, inclusive na questão de Indicadores de Desempenho. Na questão ambiental, apresenta um documento formal de seus projetos e ações ambientais, com programas de economia de energia, reciclagem e proteção da natureza implementados em sua comunidade.

Como foi possível observar, a Universidade Industrial de Santander (UIS), da Colômbia, foi a que apresentou a maior consistência no questionário aplicado. São mais de 20.000 alunos de graduação e pós-graduação, sendo 31 cursos de graduação e 126 cursos de pós-graduação, entre especializações, mestrados e doutorados.

A UIS é a responsável pela organização do Projeto SUMA. 
A média das questões com escala likert apresentadas pelo questionário respondido pela UIS foi de 4,86 , demonstrando um alto grau de desenvolvimento dos grupos do questionário, com destaques para Sustentabilidade Financeira e Responsabilidade Ambiental, em que o Concordo Totalmente foi marcado em todas as perguntas. Além disso, a parte de Tecnologia Informação apresenta-se com grande maturidade, em um sistema de ERP desenvolvido pela própria Universidade, atendendo quase todos os módulos indicados. 


\section{Considerações e Conclusões}

O modelo de gestão universitária proposto por esta dissertação, sobre o conceito de sustentabilidade, é uma tentativa de auxiliar a organização institucional das IES, chamando a atenção para questões de grande importância, tais como Excelência em Ensino e Pesquisa, Gestão Universitária, Responsabilidade Social e Responsabilidade Ambiental, e que devem ser avaliadas conjuntamente, propiciando o desenvolvimento sustentável das instituições e o impacto positivo das suas ações em seu ambiente.

É importante observar que o modelo também valoriza o papel que a Tecnologia da Informação possui nas IES, no sentido em que viabiliza a aplicação de novos conceitos e processos, sejam acadêmicos ou administrativos, melhorando assim a relação das instituições com seus clientes, fornecedores e governo.

A pesquisa desta dissertação indica um modelo de gestão universitária bem estabelecida da PUC-Rio, mesmo em relação a Universidades da América Latina e Europa. Grandes desafios de sua sustentabilidade estão sendo trilhados com planejamento e engajamento da comunidade. Contudo, as boas práticas identificadas pela pesquisa são importantes referências para desenvolvimentos internos da PUC-Rio, e devem ser avaliados pela Instituição.

Dentro das melhorias identificadas, é possível ressaltar: a necessidade de uma orçamentação plurianual, com uma visão de médio prazo que identifique consequências futuras de ações imediatas; um efetivo acompanhamento dos egressos, criando um vínculo duradouro com os ex-alunos e identificando demandas do mercado atual que possam direcionar projetos de ensino; além da convergência entre as diversas equipes de TI, caminhando para uma unificação das mesmas gerando otimização de custos e de resultados.

A vanguarda na Excelência em Ensino e Pesquisa das Instituições Privadas, seu caráter social enraizado, e o pioneirismo na Responsabilidade Ambiental indicam um momento de consolidação da PUC-Rio e de seu papel no ambiente que está inserida, auxiliados pelo retorno positivo de sua Gestão Financeira e do uso de Tecnologia da Informação.

O presente trabalho apresenta o Modelo de Gestão Universitária da PUCRio, tornando-se uma fonte de estudos e conhecimento para consultas futuras em 
seu ambiente interno.

Limitações do trabalho desenvolvido podem servir de modelo para trabalhos futuros, como:

- Estudo longitudinal da evolução da Gestão Universitária no Brasil e no Mundo;

- Maior abrangência das Universidades pesquisadas, gerando amostra suficiente para aprofundamentos estatísticos;

- Estruturação de um modelo padrão que possa avaliar a Gestão Universitária, com abrangência estratégica, das Instituições de Ensino Superior, com definições de indicadores de desempenho institucionais que permitam, ainda, a comparação de desempenho (benchmarking) entre instituições diferentes. 


\section{Referências}

ALMEIDA, M. E. B. Educação à distância na Internet: abordagens e contribuições dos ambientes digitais de aprendizagem. Educação e Pesquisa. São Paulo, v. 29, p. 327-40, jul/dez. 2003.

CAPES. Coordenação de Aperfeiçoamento de Pessoal de Nível Superior. Disponível em: < http://www.capes.gov.br>. Acesso em: 23 abr. 2012.

COMISSÃO EUROPEIA. Disponível em: $<$ http://ec.europa.eu/enterprise/policies/sustainable-business/>. Acesso em: 3 mai. 2012.

CPA PUC-Rio. Relatório de Avaliação PUC-Rio 2011, Março de 2012, 24p.

CHOU, D. C., TRIPURAMALLU, H. B., CHOU, A. Y. BI and ERP integration. Information Management \& Computer Security, v. 13, p. 340-349, 2005.

DÁVALOS, R. V.; MÜLBERT, A. L. Implantação de um sistema integrado de gestão para dar suporte às atividades administrativas e de ensino. In: XXII ENCONTRO NACIONAL DE ENGENHARIA DE PRODUÇÃO, 2002, Curitiba. Anais eletrônicos do XXII Enegep. Curitiba: ENEGEP, 2002.

ESTATUTO da Entidade Mantenedora. Pontifícia Universidade Católica do Rio de Janeiro. 2008.

FONSECA, M. L. G. Pontifícia Universidade Católica do Rio de Janeiro. Sustentabilidades e valores em projetos de desenvovlimento local: um estudo sobre o Município de Rio das Ostras. 2009, 98fls. Dissertação (Mestrado em Geografia). Pontifícia Universidade Católica do Rio de Janeiro, Rio de Janeiro 2009.

FUCAPE. Fucape Business School. Disponível em: < http://www.fucape.br>. Acesso em: 27 abr. 2012.

GARCIA, M. Três grandes tendências para o ensino superior privado no Brasil. Revista Ensino Superior, São Paulo, n. 77, p. 41-43, fev. 2005.

GARTNER. Gartner Group. Disponível em : < http://www.erpguidebooks.com/tag/gartner/>. Acesso em : 15 mar. 2012.

GIL, A. C. Métodos e Técnicas de Pesquisa Social. 5. ed. São Paulo: Atlas, 1999.

INEP. Instituto Nacional de Estudos e Pesquisas Educacionais Anísio Teixeira. Disponível em : < http://portal.inep.gov.br/>. Acesso em : 2 abr. 2012.

LAVILLE, C., DIONNE, J. A construção do saber: manual de metodologia da pesquisa em ciências humanas. Belo Horizonte: 
Editora UFMG, 1999.

LIMA, S. F. Introdução ao Conceito de Sustentabilidade : Aplicabilidade e Limites. Caderno de Escola de Negócios UNIBRASIL. v. 4, n. 4, p. 1-14, jan./dez. 2006.

LOHN, V. M. Indicadores de Responsabilidade Social: Uma Proposta para as Instituições de Ensino Superior. Revista GUAL - Universidade do Vale do Itajaí, v.4, n. 1, p.110-128, jan./abr. 2011.

MARION, J. C. Contabilidade Empresarial. São Paulo: Atlas, 2007.

NUNES, I. B. Noções de educação a distância. Revista Educação a Distância. Brasília, n. 4/5, p. 7-25, dez./abr. 1993-1994.

PUC-Rio. Pontifícia Universidade Católica do Rio de Janeiro. Disponível em: <http://www.puc-rio.br/sobrepuc/admin/>. Acesso em: 25 jan. 2012.

PUC-Rio 70 Anos - coordenadora acadêmica: Margarida de Souza Neves; coordenadora de pesquisa: Silvia llg Byington. - Rio de Janeiro: PUC-Rio, 2010. 236p.

QS RANKINGS. Country guides, course information and university rankings for undergraduate degrees. Disponível em: <http://www.topuniversities.com>. Acesso em: 26 mai. 2012.

QUEIROZ, F. C. B. P., QUEIROZ, J. V., HÉKIS, H. R. Gestão estratégica e financeira das instituições de ensino superior: um estudo de caso. IJIE Iberoamerican Journal of Industrial Engineering. Universidade Federal de Santa Catarina. Florianópolis, v. 3, n. 1, p. 98-117, Julho, 2011.

ROMANO, R. Gestão universitária, autonomia, autoritarismo. Revista USP, São Paulo, n.78, p. 48-57, junho/agosto 2008.

SOBRAL, F. A. F.. Qualidade acadêmica e relevância social e econômica da educação superior. Cad. Cedes, Campinas vol. 29, n. 78, p. 227-241, maio/ago. 2009.

SOUZA, J. C. V. Pontifícia Universidade Católica de São Paulo. Programa de Pós-Graduação em Educação e Currículo. Gestão Universitária em Instituições Particulares: os documentos institucionais como indicadores de modelo de gestão. 2007. 208f. Tese (Doutorado) - Pontifícia Universidade Católica de São Paulo, São Paulo, 2007.

SUMA. Hacia una Gestión Financiera Sostenible de las Universidades en América Latina. Disponível em: < http://www.suma-network.org>. Acesso em 27 mai. 2012.

TACHIZAWA, T. Gestão ambiental e responsabilidade social corporativa: estratégias de negócios focadas na realidade brasileira. São Paulo: Atlas, 2002. 
TAUCHEN, J., BRANDLI, L. L. A Gestão Ambiental em Instituições de Ensino Superior: Modelo para Implantação em Campus Universitário. Gestão \& Produção, v. 13, n. 3, p. 503-515, set.-dez. 2006.

UNESCO. Global Education Digest 2011 - Unesco Institute For Statistics 2011. Disponível em: < http://www.uis.unesco.org/>. Acesso em: 25 fev. 2012.

WELSCH, G. A. Orçamento empresarial. São Paulo: Atlas, 1973.

YIN, R. K. Estudo de Caso: planejamento e métodos. Porto Alegre: Bookman, 2005. 


\section{ANEXOS}

\section{ANEXO A}

Respostas abertas dos questionários aplicados:

Questão 1.9) $\mathrm{Na}$ sua opinião, quais são os investimentos necessários para a manutenção da excelência acadêmica na sua Universidade?

Respostas:

Infraestrutura, Inovação Tecnológica, Capacitação do Capital Humano, Laboratórios, Investimentos em TI.

Capacitação e atualização dos Docentes. Excelência de laboratórios certificados.

Capacitação e formação de docentes. Equipamentos acadêmicos.

Equipe e software

Capacitação docente com relação a novas tecnologias.

Elevar o nível acadêmico dos docentes (apenas 19\% com pós-graduação).

Os necessários para cumprir com os programas de estudo.

Professores de alto nível e tecnologias atualizadas.

Investimentos em capital humano e apoio para as atividades de pesquisa e de cultura.

Novas tecnologias, laboratórios, salários competitivos para captação dos melhores professores e pesquisadores.

Capacitação de pessoal, Bolsas, Infraestrutura e equipe. 
Questão 2.6) Na sua opinião, quais são os grandes desafios da sustentabilidade financeira para a Universidade?

Respostas:

Tratar de buscar a geração própria de fundos e parcerias com outras instituições que fornecem fundos para não depender exclusivamente do Estado.

Diversificação das fontes de financiamento. Decrescente financiamento público, crescente competência entre outras universidades, motivando para poder oferecer salários competitivos.

A redução dos aportes do Estado e o incremento dos compromissos.

Cumprir metas de receitas financeiras (mensalidades e doações). Ajustar os orçamentos de gastos.

O controle de gastos e investimentos.

Buscar fontes alternativas de recursos para não depender exclusivamente de fundos estatais.

Diversificar as fontes de financiamento.

Diversificação das fontes de financiamento. Controle de eficiência nos gastos. Modernização da gestão institucional.

Obter fundos do Governo Central. Desenvolver projetos e programas acadêmicos que geram fundos.

Captação de outros recursos não provenientes de deveres. O financiamento estatal. A qualidade do gasto. A diversificação de fontes de financiamento.

Por ser uma universidade privada sem fins lucrativos, tem como desafio a sustentabilidade financeira, com o incremento de estudantes para aumentar o ingresso de recursos, além de projetos que possam gerar de fundos de gestão. 


\section{APÊNDICES}

\section{APÊNDICE A}

Questionário aplicado

Nome:

\section{Universidade:}

Para cada item abaixo, assinale com um X o número de 1 até 5 que representa a interpretação da afirmativa segundo a realidade da Universidade, sendo:

\section{1 = Discordo Totalmente $e$ 5 = Concordo Totalmente.}

\section{Excelência em Ensino e Pesquisa}

\begin{tabular}{|l|l|l|l|l|}
\hline \multicolumn{1}{l|}{$\begin{array}{l}\text { 1.1) A Universidade possui um Grupo de Avaliação do } \\
\text { desempenho acadêmico de seus Professores. }\end{array}$} & $\mathbf{1}$ & $\mathbf{3}$ & $\mathbf{4}$ & $\mathbf{5}$ \\
\hline $\begin{array}{l}\text { 1.2) A Universidade possui uma Empresa Júnior. } \\
\text { 1.3) A Universidade possui uma unidade de inovação e } \\
\text { empreendedorismo. }\end{array}$ & & & \\
\hline $\begin{array}{l}\text { 1.4) Os professores participam de Projetos de Pesquisa. } \\
\text { 1.5) Os alunos participam de Projetos de Pesquisa. }\end{array}$ & & & & \\
\hline $\begin{array}{l}\text { 1.6) A Universidade investe na aquisição de livros, periódicos e } \\
\text { base de dados para sua biblioteca. }\end{array}$ & & & & \\
\hline $\begin{array}{l}\text { 1.7) A Universidade possui uma estrutura de Ensino à Distância } \\
\text { (EAD). }\end{array}$ & & & & \\
\hline $\begin{array}{l}\text { 1.8) A Universidade possui um sistema de acompanhamento de } \\
\text { egressos. }\end{array}$ & & & & \\
\hline
\end{tabular}

1.9)Na sua opinião, quais são os investimentos necessários para a manutenção da excelência acadêmica na sua Universidade?

\section{Gestão Financeira}

2.1) A universidade estabelece um Planejamento Financeiro, definindo metas de despesas e investimentos para os próximos meses.

2.2) São realizadas reuniões para comparar os valores planejados e realizados.

2.3) A universidade identifica as fontes de recursos necessárias para o financiamento da Universidade.

\begin{tabular}{l|lll|l|l|}
1 & 2 & 3 & 4 & 5 \\
\hline
\end{tabular} 


\begin{tabular}{|l|l|l|l|}
\hline $\begin{array}{l}\text { 2.4) A universidade realiza planejamento financeiro de médio e } \\
\text { longo prazo. }\end{array}$ & & & \\
\hline $\begin{array}{l}\text { 2.5) A universidade possui uma estrutura interna de planejamento } \\
\text { financeiro e orçamentário. }\end{array}$ & & & \\
\hline
\end{tabular}

2.6) Na sua opinião, quais são os grandes desafios da sustentabilidade financeira para a Universidade?

\section{$\underline{\text { 3. Tecnologia da Informacão }}$}

3.1) A universidade possui um sistema formal de ERP (Enterprise Resource Planning)?

( ) SIM ( ) NÃO

3.2) Caso afirmativo, como foi feito o desenvolvimento do ERP?
( ) In house
( ) Pacote de Terceiros
( ) Mixto
Não se aplica

3.3) Qual a faixa percentual que a Universidade dispende na manutenção dos sistemas de TI administrativos e acadêmicos em relação ao gasto total?
( ) $<1 \%$
( ) $>5 \%$
( ) $1 \%-2 \%$
( ) $2-5 \%$

3.4) Por favor, identifique com um " $X$ " todos os módulos que o seu sistema suporta:

( ) Matrícula

( ) Bolsas

( ) Faturamento

( ) Avaliação Acadêmica

( ) Gestão de Notas

( ) Avaliação Interna de

Professores

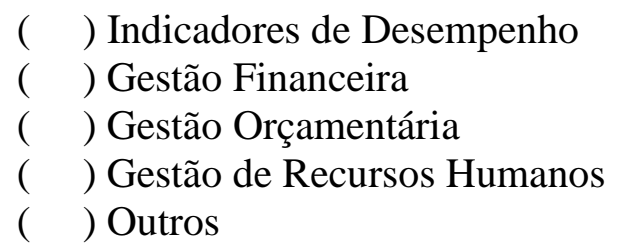

\section{Responsabilidade Ambiental}

4.1) A universidade possui documento formal de projetos e ações voltadas para a sustentabilidade ambiental.

4.2) A universidade possui um setor específico voltado para a sustentabilidade ambiental. 


\begin{tabular}{|l|l|l|l|}
\hline $\begin{array}{l}\text { 4.3) A Universidade já tentou reduzir o impacto ambiental da sua } \\
\text { universidade em termos de: }\end{array}$ & \multicolumn{3}{|l|}{} \\
\hline Economia de energia. & & & \\
\hline Minimização e reciclagem de resíduos. & & & \\
\hline Proteção da Natureza. & & & \\
\hline
\end{tabular}

\section{Responsabilidad Social}

5.1) A universidade proporciona oportunidades de formação a mebros da comunidade local (como, por exemplo, estágios ou oportunidades de trabalho para jovens ou pessoas pertencentes a grupos desfavorecidos).

5.2) Dispõe de um canal aberto de diálogo com a comunidade local sobre questões desfavoráveis.

5.3) Os seus funcionários são incentivados a participar de atividades com a comunidade local.

5.4) A universidade oferece apoio financeiro para projetos com a comunidade local.

\begin{tabular}{|l|l|l|l|l|l|l|l|l|l}
\hline 1 & 2 & 3 & 4 & 5 \\
\hline
\end{tabular} 